\section{Contact Sensitization in Patients With Lower Leg Dermatitis, Chronic Venous Insufficiency, and/ or Chronic Leg Ulcer: Assessment of the Clinical Relevance of Contact Allergens}

\author{
Erfurt-Berge $\mathrm{C}^{1}$, Mahler $\mathrm{V}^{1^{*}}$ \\ ${ }^{1}$ Department of Dermatology, University Hospital Erlangen, \\ Erlangen, Germany \\ ${ }^{*}$ Current address: Paul-Ehrlich-Institut, Langen, Germany
}

J Investig Allergol Clin Immunol 2017; Vol. 27(6): 378-380 doi: $10.18176 /$ jiaci.0188

Key words: Chronic leg ulcer. Contact sensitization. Allergic contact dermatitis, Wound dressing.

Palabras clave: Úlcera de pierna crónica. Sensibilización de contacto. Dermatitis de contacto alérgica. Apósito para heridas.

The Information Network of Departments of Dermatology (IVDK) is a network of 57 dermatology clinics that collects patch testing data. We assessed patients with lower leg dermatitis (LLD), chronic venous insufficiency (CVI), and/or chronic leg ulcer (CLU) during 2004-2013 and compared our results with those from the period 1994-2003 in the IVDK cohort. We recently found that the frequency of contact sensitization to most contact allergens had declined significantly (44.8\% of patients in 2004-2013 had at least 1 positive test reaction vs $58.6 \%$ in $1994-2003$ ). However, the allergen spectrum remained largely unchanged. Moreover, a significant decrease in the frequency of allergic contact dermatitis (ACD) was observed between the 2 periods (final diagnosis of ACD in $25.9 \%$ of patients in $1994-2003$ vs $16.9 \%$ in 2004-2013) [1]. In our previous study, we could not provide a detailed analysis of the clinical relevance of sensitizations identified in patients with LLD, CVI, and/or CLU, the patients' own materials (eg, topical drugs, wound dressings), and the pathogenesis of CLU [1].

We studied a subgroup of the IVDK cohort [1] from a single center (Department of Dermatology, University Hospital of Erlangen, Germany) to investigate the etiology and pathogenesis of CLU in patch-tested individuals, the clinical relevance of positive patch-test reactions, and the clinical relevance of the patients' own materials (ie, wound dressings and topical ointments)

Of the entire patch test cohort $(\mathrm{N}=3782), 52$ patients with LLD, CVI, and/or present or previous CLU (26 male, 26 female; median age, 73 years) were patch tested between 2004 and 2013 according to DKG guidelines [2] using 8-mm
Finn Chambers on Scanpor tape. Exposure time was 48 hours in all patients. We analyzed the series tested in all 52 patients (ie, DKG standard series, DKG ointment base series), as well as the patients' own substances (individual wound dressings and topical treatments), which were tested selectively in 39 patients. The clinical relevance of positive reactions was assessed individually in all cases by a senior fellow.

A total of 42 patients $(80.7 \%$ ) with present or previous CLU were identified within the patch test cohort. CVI was its most frequent cause $(n=27,64.3 \%)$ in all CLU patients, followed by arterial occlusive disorder $(n=7,16.7 \%)$, posttraumatic healing by secondary intention $(\mathrm{n}=5,11.9 \%)$, and unspecified causes $(n=3,7.1 \%)$.

Of all patients tested, $28(53.8 \%)$ had at least 1 positive reaction. In total, 87 positive reactions were observed; of these, $56(64 \%)$ were considered to be of current relevance $(n=47)$ or past relevance $(n=9)$. In 26 patients $(50 \%)$, an active ulcer was present at the time of the patch test. The contact allergens identified as clinically relevant in more than $5 \%$ of tested individuals were tertiary butyl-hydroquinone, Amerchol-L101, balsam of Peru, fragrance mix II, cetearyl alcohol, lanolin alcohols, cocamidopropyl betaine, and propylene glycol (Table).

In total, 132 patients' own materials, ie, wound care products $(n=52)$ and topical ointments $(n=80)$, were tested individually in 39 of the 52 patients $(75.0 \%)$. Seven positive reactions $(5.3 \%$ of the 132 materials tested) were identifiedprimarily among wound care products, not topical ointmentsand were considered clinically relevant (Table).

The sensitization rate of $53.8 \%$ in the subgroup was higher than that recently reported from the IVDK cohort [1], indicating specific patient selection with a high suspicion of ACD. In CLU/LLD/CVI patients, contact sensitization against the contact allergens tert-butyl hydroquinone, Amerchol-L101, balsam of Peru, fragrance mix II, cetearyl alcohol, and lanolin alcohols (with sensitization rates $\geq 10 \%$ ) is not only frequent [3-5], but also - if positive patch test reactions are present - clinically relevant in most cases $(>50 \%)$, whereas positive reactions to nickel sulfate are not. Reactions against topical antibiotics [6] were observed occasionally, since the DKG series for topical antibiotics was not tested regularly in all patients.

In a recent French study (354 patients tested with 10 wound care products), the authors reported a $19.2 \%$ rate of sensitization to wound care products [7]. Previous studies from Germany revealed positive test reactions to wound care products in 5.7\% [8] and 17\% [9] of patients tested. Despite the broad acceptance and tolerability of modern wound care products, contact allergy to modern wound dressings is possible, and patch testing should be performed when ACD is suspected. Wound dressings are medical devices, for which 
full labelling is not regulated, in contrast with pharmaceutical products [10], thus making it difficult to identify the culprit component.
In conclusion, evidence-based strategies for wound therapy need to be implemented in order to avoid skin exposure, at least to the most frequent clinically

Table. Results of Patch Testing ${ }^{a}$

\begin{tabular}{|c|c|c|c|c|}
\hline Commercial PT Preparation $^{\mathrm{b}}$ & $\begin{array}{c}\text { Test } \\
\text { Concentration* }\end{array}$ & $\begin{array}{l}\text { Patients With } \\
\text { Positive Test } \\
\text { Reaction to } \\
\text { This Contact } \\
\text { Allergen } \\
\left(\mathrm{n}_{\text {tested }}=52\right)\end{array}$ & $\begin{array}{c}\text { Patients With } \\
\text { Positive Test Reaction } \\
\text { And Clinical Relevance } \\
\text { for This Contact } \\
\text { Allergen, No. }(\%) \\
\quad\left(\mathrm{n}_{\text {tested }}=52\right)\end{array}$ & $\begin{array}{c}\text { Clinically Relevant } \\
\text { PT Reactions out of } \\
\text { Positive PT Reactions } \\
\text { for This Contact } \\
\text { Allergen, No. }(\%)\end{array}$ \\
\hline Tertiary-Butyl hydroquinone & $1 \%$ & $10(19.23 \%)$ & $6(11.5 \%)$ & $\mathrm{n}=6 / 10(60 \%)$ \\
\hline Amerchol L-101 & $50 \%$ & $9(17.3 \%)$ & $8(15.4 \%)$ & $\mathrm{n}=8 / 9(88.9 \%)$ \\
\hline Balsam of Peru (Myroxylon pereirae) & $25 \%$ & $7(13.5 \%)$ & $4(7.7 \%)$ & $\mathrm{n}=4 / 7(57.1 \%)$ \\
\hline Fragrance Mix II & $14 \%$ & $7(13.5 \%)$ & $4(7.7 \%)$ & $\mathrm{n}=4 / 7(57.1 \%)$ \\
\hline Cetearyl alcohol & $20 \%$ & $6(11.5 \%)$ & $5(9.6 \%)$ & $\mathrm{n}=5 / 6(83.3 \%)$ \\
\hline Lanolin alcohols & $30 \%$ & $5(9.6 \%)$ & $4(7.7 \%)$ & $\mathrm{n}=4 / 5(80 \%)$ \\
\hline Nickel sulfate & $5 \%$ & $4(7.7 \%)$ & $0(0 \%)$ & $\mathrm{n}=0 / 4(0 \%)$ \\
\hline Cocamidopropyl betaine & $1 \% \mathrm{aq}$ & $4(7.7 \%)$ & $3(5.8 \%)$ & $\mathrm{n}=3 / 4(75 \%)$ \\
\hline Colophony & $20 \%$ & $3(5.8 \%)$ & $1(1.9 \%)$ & $\mathrm{n}=1 / 3(33.3 \%)$ \\
\hline Fragrance mix I & $8 \%$ & $3(5.8 \%)$ & $2(2.8 \%)$ & $\mathrm{n}=2 / 3(66.7 \%)$ \\
\hline Propolis & $10 \%$ & $3(5.8 \%)$ & $1(1.9 \%)$ & $\mathrm{n}=1 / 3(33.3 \%)$ \\
\hline Compositae mix & $5 \%$ & $3(5.8 \%)$ & $0(0 \%)$ & $\mathrm{n}=0 / 3(0 \%)$ \\
\hline Propylene glycol & $20 \%$ aq & $3(5.8 \%)$ & $3(5.8 \%)$ & $\mathrm{n}=3 / 3(100 \%)$ \\
\hline Benzophenone-4 (Sulisobenzone) & $10 \%$ & $3(5.8 \%)$ & $1(1.9 \%)$ & $\mathrm{n}=1 / 3(33.3 \%)$ \\
\hline p-tertiary-Butylphenol formaldehyde resin & $1 \%$ & $2(3.8 \%)$ & $0(0 \%)$ & $\mathrm{n}=0 / 2(0 \%)$ \\
\hline Methyldibromo glutaronitrile & $0.2 \%$ & $2(3.8 \%)$ & $1(1.9 \%)$ & $\mathrm{n}=1 / 2(50 \%)$ \\
\hline Octyl gallate & $0.3 \%$ & $2(3.8 \%)$ & $1(1.9 \%)$ & $\mathrm{n}=1 / 2(50 \%)$ \\
\hline Butylated Hydroxyanisole (BHA) & $2 \%$ & $2(3.8 \%)$ & $0(0 \%)$ & $\mathrm{n}=0 / 2(0 \%)$ \\
\hline Paraben mix & $16 \%$ & $1(1.9 \%)$ & $1(1.9 \%)$ & $\mathrm{n}=1 / 1 / 100 \%)$ \\
\hline Bufexamac & $5 \%$ & $1(1.9 \%)$ & $1(1.9 \%)$ & $\mathrm{n}=1 / 1(100 \%)$ \\
\hline Polyethylene glycol ointment (DAB 8) & pure & $1(1.9 \%)$ & $1(1.9 \%)$ & $n=1 / 1(100 \%)$ \\
\hline Patients' Own Wound Care Products ${ }^{\mathrm{c}}$ & $\begin{array}{c}\text { Test } \\
\text { Concentration }\end{array}$ & $\begin{array}{c}\text { Patients With } \\
\text { Positive Test } \\
\text { Reaction to } \\
\text { This Allergen } \\
\text { (From Number of } \\
\text { of Patients Tested), } \\
\text { No. (\%) }\end{array}$ & $\begin{array}{c}\text { Patients With } \\
\text { Positive Test Reaction } \\
\text { and Clinical Relevance } \\
\text { for This Allergen } \\
\text { No. }(\%)\end{array}$ & $\begin{array}{c}\text { Clinically Relevant } \\
\text { PT Reactions out of } \\
\text { Positive PT Reactions } \\
\text { for This Contact } \\
\text { Allergen, No. }(\%)\end{array}$ \\
\hline Foam dressing & Pure & $\mathrm{n}=1 / 8(12.5 \%)$ & $\mathrm{n}=1 / 8(12.5 \%)$ & $\mathrm{n}=1 / 1(100 \%)$ \\
\hline $\begin{array}{l}\text { Antiseptic agent (containing } \\
\text { octenidine hydrochloride) }\end{array}$ & Pure & $\mathrm{n}=2 / 3(66.6 \%)$ & $\mathrm{n}=2 / 3(66.6 \%)$ & $\mathrm{n}=2 / 2(100 \%)$ \\
\hline Enzymatic wound ointment & Pure & $\mathrm{n}=2 / 4(50 \%)$ & $\mathrm{n}=2 / 4(50 \%)$ & $\mathrm{n}=2 / 2(100 \%)$ \\
\hline Hydrocolloid dressing & Pure & $\mathrm{n}=1 / 3(33.3 \%)$ & $\mathrm{n}=1 / 3(33.3 \%)$ & $\mathrm{n}=1 / 1(100 \%)$ \\
\hline Antibiotic cream & Pure & $\mathrm{n}=1 / 4(25 \%)$ & $\mathrm{n}=1 / 4(25 \%)$ & $\mathrm{n}=1 / 1(100 \%)$ \\
\hline
\end{tabular}

aThe vehicle was petrolatum unless otherwise indicated.

${ }^{b}$ Patch test reactions $(n=1)$ without clinical relevance (ie, for potassium dichromate, thiuram mix, cobalt chloride, zinc diethyl dithiocarbamate, triethanolamine, and butyl hydroxytoluene) are not shown.

${ }^{\mathrm{c}}$ The number of patients varies due to individual testing. 
relevant contact allergens (tertiary butyl hydroquinone, Amerchol-L101, balsam of Peru, and fragrance mix II). The allergenic potential of modern wound dressings should not be underestimated [11]. A correlation between the number of sensitizations to wound dressings and wound duration has been observed [9,11]. Patch testing of individual topical preparations and modern wound dressings should be performed when ACD is suspected in CLU/LLD/CVI patients. The impact of modern wound dressings in the induction of $\mathrm{ACD}$ requires further study.

\section{Funding}

The authors declare that no funding was received for the present study.

\section{Conflicts of Interest}

V Mahler has no conflicts of interest to declare. C ErfurtBerge has received travel grants and honoraria from BSN Medical GmbH, Lohmann \& Rauscher GmbH \& Co.KG, Smith \& Nephew, and Urgo GmbH for scientific lectures on the topic of chronic leg ulcers and wound care.

\section{References}

1. Erfurt-Berge C, Geier J, Mahler V. Current spectrum of contact sensitization in patients with chronic leg ulcers or stasis dermatitis - new data from the Information Network of Departments of Dermatology (IVDK). Contact Dermatitis. 2017; doi: 10.1111/cod.12763 (epub ahead of print).

2. Schnuch A, Aberer W, Agathos M, Becker D, Brasch J, Elsner $P$, et al. [Performing patch testing with contact allergens]. J Dtsch Dermatol Ges. 2008;6:770-5.

3. Renner R, Wollina U. Contact sensitization in patients with leg ulcers and/or leg eczema: comparison between centers. Int J Low Extrem Wounds. 2002;1:251-5.

4. Reich-Schupke S, Kurscheidt J, Appelhans C, Kreuter A, Altmeyer P, Stucker M. [Patch testing in patients with leg ulcers with special regard to modern wound products]. Hautarzt. 2010; 61: 593-7.

5. Lange-lonescu S, Pilz B, Geier J, Frosch PJ. [Kontaktallergien bei Patienten mit Stauungsdermatitis oder Ekzem der Beine]. Dermatosen in Beruf und Umwelt. 1996;44:14-22.

6. Escobosa M, Quesada M, Cruz Granados S, Amat Lopez J. Contact Dermatitis to Antibiotic Ointments. J Investig Allergol Clin Immunol. 2009;19:510-1.

7. Valois A, Waton J, Avenel-Audran M, Truchetet F, Collet E, Raison-Peyron $\mathrm{N}$, et al. Contact sensitization to modern dressings: a multicentre study on 354 patients with chronic leg ulcers. Contact Dermatitis. 2015;72:90-6.

8. Lehnen M, Kohaus S, Korber A, Hillen U, Grabbe S, Dissemond J. [Contact allergies in patients with chronic wounds: results of a study from 1999 to 2004]. Hautarzt. 2006;57:303-6, 308.

9. Renner R, Simon JC, Treudler R. Contact sensitization to modern wound dressings in 70 patients with chronic leg ulcers. Dermatitis. 2013;24:60-3.
10. Council Directive 93/42/EEC of 14 June 1993 concerning medical devices, No L169/1, paragraph 13.3 b;

11. Cueva Oliver B, González Delgado P. Contact Sensitization to Modern Wound Dressing. In: Mackay I, Rose N, Ledford D, Lockey R, editors. Encyclopedia of Medical Immunology: Allergic Diseases: Springer New York; 2014. p. 186-9.

Manuscript received May 18, 2017; accepted for publication July 13, 2017.

Cornelia Erfurt-Berge

Department of Dermatology University Hospital Erlangen Ulmenweg 18 91054 Erlangen E-mail: Cornelia.Erfurt-Berge@uk-erlangen.de 


\section{Food Protein-Induced Enterocolitis Syndrome in Response to Quail's Egg in a Child Without Hen's Egg Allergy}

\author{
Akashi $\mathrm{M}^{1,2}$, Sato $\mathrm{S}^{1}$ \\ ${ }^{1}$ Department of Pediatrics, Saitama City Hospital, Saitama, Japan \\ ${ }^{2}$ Department of Pediatrics, Keio University School of Medicine, \\ Tokyo, Japan
}

J Investig Allergol Clin Immunol 2017; Vol. 27(6): 381-382 doi: 10.18176/jiaci.0190

Key words: Food protein-induced enterocolitis syndrome. Quail's egg. Hen's egg. Lymphocyte stimulation test.

Palabras clave: Síndrome de enterocolitis inducido por proteína alimentaria. Huevo de codorniz. Huevo de gallina. Test de estimulación linfocitaria.

Given that clinical and serological cross-reactivity between hen and quail egg proteins is common [1,2], reports of patients with quail's egg allergy without hen's egg allergy are very rare [3-5].

We report the case of a patient without hen's egg allergy who experienced food protein-induced enterocolitis syndrome (FPIES) in response to eating quail's egg. The diagnosis was based on double-blind, placebo-controlled food challenge (DBPCFC) and a positive result to quail's egg in the lymphocyte stimulation test (LST).

The patient was a 6-year-old girl who visited the hospital with a 3-year history of repetitive vomiting and pallor 2 hours after eating cooked quail's egg.

She could eat raw hen's egg without experiencing an allergic reaction and had no other allergic diseases, such as asthma, atopic dermatitis, or other food allergy. Her father and elder brother have pollen allergy, and her mother has house dust mite allergy.

The results of skin prick tests with raw quail's egg and raw hen's egg were negative. The results of specific IgE testing with hen's egg white, yolk, and ovomucoid were under $0.10 \mathrm{kU}_{\mathrm{A}} / \mathrm{L}$.

After obtaining informed consent from the patient's parents, we performed DBPCFC for quail's egg, with hen's egg used as a control. The patient's mother fried quail's egg or hen's egg (amount equivalent to a quail's egg: $9 \mathrm{~g}$ ) at home and brought them to our hospital on the days of the DBPCFC.

The result of the food challenge test for hen's egg was negative, while the test for quail's egg was positive. Nausea, repetitive vomiting, pallor, and lethargy began 160 minutes after ingestion of quail's egg and were treated with intravenous saline solution. The patient's condition improved 4 hours after ingestion of quail's egg.

An LST was performed with raw quail's egg and hen's egg, and the results were evaluated by a commercial laboratory testing service (BML, Tokyo, Japan).

Briefly, the patient's mononuclear cells and antigen solution were incubated for 3 days. They were then incubated for an additional 24 hours with a $3 \mathrm{H}$-thymidine solution. After the cells were washed and lysed, the quantity of $3 \mathrm{H}$-thymidine absorbed was measured. The stimulation index (SI) was calculated according to the following formula: $\mathrm{SI}=3 \mathrm{H}$-thymidine absorption of mononuclear cells with/without antigen. An SI value $>1.8$ was considered positive. The SI for quail's egg was 1.9 (positive); the SI for hen's egg was 1.0 (negative).

We present a rare case of a patient with FPIES to quail's egg without allergy to hen's egg. FPIES is a non-IgE-mediated gastrointestinal food allergy characterized by repetitive vomiting, lethargy, and pallor within 1 to 4 hours of ingestion. Our case meets the diagnostic criteria proposed by NowakWęgrzyn et al $[6,7]$.

Serological cross-reactivity between hen and quail egg proteins has been reported [1]. As for clinical cross-reactivity, Alessandri et al [2] reported that all 15 children with a positive skin prick result to hen's egg showed positive skin prick results to quail's egg. Moreover, both domestic hen (Gallus domesticus) and quail (Coturnix coturnix) belong to the family Galliformes.

FPIES is a non-IgE-mediated gastrointestinal food allergy in which T cells are believed to play an important role [8]. We performed LST for hen's egg and quail's egg. Although the utility of LST for diagnosis of FPIES is controversial, LST is theoretically suitable for the diagnosis of FPIES, which is thought to be cell-mediated [9]. The results of the LST were positive to quail's egg (ie, causative antigen) but negative to hen's egg (ie, tolerated antigen). These results were compatible with the clinical manifestations.

Although reports of FPIES to hen's egg are common [10], few authors have examined the clinical or hematological association between hen's egg and quail's egg for non-IgEmediated gastrointestinal food allergies, including FPIES.

The concurrent rate of non-IgE-mediated gastrointestinal food allergies to hen's egg and quail's egg might be lower than that of IgE-mediated food allergy to hen's egg and quail's egg.

To date, only 3 reports of quail's egg allergy without hen's egg allergy have been published. The first case involved a 10.5-year-old girl who presented an anaphylactic reaction after eating uncooked quail's egg [3]. The second involved 5 patients who had angioedema or anaphylaxis after eating undercooked quail's egg [5]. These cases were all IgE-mediated allergic reactions. The final case was that of a 3-year-old girl who presented with FPIES after eating a boiled quail's egg [4]. It is interesting that the allergic reaction was non-IgE-mediated in all patients (including the present case) who reacted to cooked quail's egg, whereas it was IgE-mediated in those who reacted to uncooked or undercooked quail's egg.

Further investigation of patients with FPIES to quail's egg who are not allergic to hen's egg may help to elucidate the mechanism underlying non-IgE-mediated gastrointestinal food allergies.

\section{Funding}

The authors declare that no funding was received for the present study.

\section{Conflicts of Interest}

The authors declare that they have no conflicts of interest. 


\section{References}

1. Takahashi K, Horiguchi M, Bando N, Tsuji H, Ogawa T, Asao T. Immunochemical characterization of ovomucoid from Japanese quail egg white using monoclonal antibodies. J Nutr Sci Vitaminol (Tokyo). 1999;45:491-500.

2. Alessandri C, Calvani M Jr, Rosengart L, Madella C. Anaphylaxis to quail egg. Allergy. 2005;60:128-9.

3. Caro Contreras FJ, Giner Muñoz MT, Martin Mateos MA, Plaza Martin AM, Sierra Martinez Jl, Lombardero M. Allergy to quail's egg without allergy to chicken's egg. case report. Allergol Immunopathol (Madr). 2008;36:234-7.

4. Sanlidag B, Babayigit Hocaoglu A, Bahceciler N. Quail's egg-induced severe enterocolitis in a child tolerant to hen's egg: first reported case. J Investig Allergol Clin Immunol. 2016;26:118-9.

5. Micozzi S, Bartolomé B, Sanchís-Merino ME, Alfaya T, Aldunate T, Diaz $M$, et al. Hypersensitivity to quail egg proteins: what about hen egg? J Investig Allergol Clin Immunol. 2016;26:316-8.

6. Nowak-Węgrzyn A, Chehade M, Groetch ME, Spergel JM, Wood RA, Allen K, et al. International consensus guidelines for the diagnosis and management of food protein-induced enterocolitis syndrome: Executive summary-Workgroup Report of the Adverse Reactions to Foods Committee, American Academy of Allergy, Asthma \& Immunology. J Allergy Clin Immunol. 2017;139:1111-26.

7. Nowak-Węgrzyn A, Jarocka-Cyrta E, Moschione Castro A. Food Protein-Induced Enterocolitis Syndrome. J Investig Allergol Clin Immunol. 2017;27:1-18.

8. Nowak-Wegrzyn A, Katz Y, Mehr SS, Koletzko S. Non-lgEmediated gastrointestinal food allergy. J Allergy Clin Immunol. 2015;135:1114-24.

9. Morita H, Nomura I, Matsuda A, Saito H, Matsumoto K. Gastrointestinal food allergy in infants. Allergol Int. 2013;62:297-307

10. Caubet JC, Nowak-Wegrzyn A. Food protein-induced enterocolitis to hen's egg. J Allergy Clin Immunol. 2011;128:1386-8.

Manuscript received May 9, 2017; accepted for publication July 26, 2017.

$\begin{array}{r}\text { Masayuki Akashi } \\ \text { Department of Pediatrics, Saitama City Hospital, Saitama, } \\ \text { Japan }\end{array}$
Mimuro 2460, Midori-ku, Saitama city, Saitama 336-8522,
Japan
E-mail: yuki0820@trust.ocn.ne.jp

A Case of Hypocomplementemic Urticarial Vasculitis Syndrome Successfully Treated With Omalizumab

Nucera $\mathrm{E}^{1 *}$, Basta $\mathrm{F}^{2 *}$, Buonomo $\mathrm{A}^{1}$, Mezzacappa $\mathrm{S}^{1}$, Margiotta $\mathrm{DP}^{2}$, Antonelli Incalzi $\mathrm{R}^{3}$, Schiavino $\mathrm{D}^{1}$

${ }^{1}$ Allergy Unit, Università Cattolica del Sacro Cuore - Policlinico

"A. Gemelli", Rome, Italy

${ }^{2}$ Unit of Allergology, Immunology and Rheumatology, Department of Medicine, Campus Bio-Medico di Roma University, Rome, Italy ${ }^{3}$ Unit of Geriatrics, Campus Bio-Medico University, Rome, Italy *Both authors contributed equally to the manuscript.

J Investig Allergol Clin Immunol 2017; Vol. 27(6): 382-384 doi: 10.18176/jiaci.0191

Key words: HUVS. Omalizumab. Hypocomplementemic urticarial vasculitis syndrome. Chronic urticarial. Lupus.

Palabras clave: Síndrome de vasculitis urticarial hipocomplementémica. Urticaria crónica. Lupus.

Hypocomplementemic urticarial vasculitis syndrome (HUVS) is a rare small-vessel vasculitis of unknown etiology first described by McDuffie et al [1] in 1973. According to the diagnostic criteria proposed by Schwartz et al [2] in 1982, the diagnosis of HUVS requires the simultaneous presence of 2 major criteria (recurrent urticaria for $>6$ months and hypocomplementemia) plus 2 or more minor criteria (biopsyproven vasculitis of the dermis, positive C1q antibody and/ or suppressed C1q titer, glomerulonephritis, arthralgia/ arthritis, ocular inflammation, and recurrent abdominal pain). Nevertheless, a variety of additional clinical findings, including angioedema and central nervous system and pulmonary involvement, have subsequently been reported [3]. Idiopathic HUVS is prevalent, although up to $50 \%$ of patients have an associated autoimmune disease [3], primarily systemic lupus erythematosus or Sjogren syndrome. Management of HUVS is very challenging: while oral antihistamines are merely palliative, hydroxychloroquine, colchicine, and corticosteroids are first-line therapy, with a complete cutaneous response achieved in fewer than $50 \%$ patients. The addition of other immunosuppressive drugs, such as azathioprine, mycophenolate mofetil, methotrexate, and ciclosporin A increases cutaneous response rates to $70 \%$ and is strongly recommended in the case of pulmonary and/or renal involvement. Cyclophosphamide and rituximab are restricted to refractory, relapsing, and/or severe disease, since they are burdened by a higher incidence of adverse effects, as are high-dose corticosteroids and cyclophosphamide [3]. Omalizumab, a humanized anti-IgE monoclonal antibody recently approved for the treatment of chronic spontaneous urticaria and successfully used in cases of severe or refractory urticaria [4], was recently shown to be ineffective in a patient with HUVS [5].

We present the case of a 47-year-old woman with no relevant comorbidities who was referred to our allergy department with a 3-year history of generalized, itchy, and 
burning daily flares of urticaria. She also complained of arthralgia, abdominal pain, and diarrhea. On admission, physical examination revealed erythematous and violaceous annular urticarial maculopapular lesions predominantly involving the trunk, abdomen, and legs. Physical and ultrasound examination revealed symmetric arthritis of the second and third proximal phalangeal and metacarpal joints. Blood test results were normal, with the exception of marked complement $\mathrm{C} 3$ depletion (C3 $0.17 \mathrm{~g} / \mathrm{L}$, normal range 0.9-1.8). Immunological screening revealed normal serum levels of antinuclear antibody, anti-double-stranded DNA, rheumatoid factor, anti-cyclic citrullinated peptide, C1q, and anti-C1q. The patient also underwent colonoscopy. Coproculture was performed, as was testing to detect parasites and Clostridium difficile in stool, although no significant abnormalities were detected. Abdominal ultrasonography and 24-hour proteinuria were both negative. The patient did not report exacerbation of symptoms after food ingestion, although skin prick tests with the commercial extracts of common allergenic foods and physical tests yielded negative results. The patient had no infections, no apparent major organ involvement, normal IgE serum levels, and normal thyroid parameters. A skin biopsy revealed perivascular and dermal eosinophilic infiltrates, with focal vessel damage confirming urticarial vasculitis. Given that 2 major criteria (recurrent urticaria $>6$ months and hypocomplementemia) and 3 minor criteria (arthralgia/arthritis, recurrent abdominal pain, and biopsyproven vasculitis of the dermis) were fulfilled, the patient was diagnosed with HUVS (Table). Therefore, antihistamines (up to 4 times per day) were combined with hydroxychloroquine (200 $\mathrm{mg} /$ day $)$ and prednisone $(0.5 \mathrm{mg} / \mathrm{kg}$, tapered to $0.1 \mathrm{mg} / \mathrm{kg})$, leading to a significant improvement in arthralgia but no response for gastrointestinal involvement and urticaria (weekly Urticarial Activity Score [UAS7], 32/42). Ciclosporin A (3 mg/kg) was administered, although it was soon suspended because of worsening of diarrhea. Omalizumab $300 \mathrm{mg}$ monthly was added. After the second injection, complete remission of gastrointestinal symptoms and urticaria was achieved (UAS7, $0 / 42$ ) and maintained for the entire duration of the treatment (25 weeks). Serum complement levels returned to normal, thus enabling gradual discontinuation of prednisone. One

Table. Diagnostic Criteria of Hypocomplementemic Urticarial Vasculitis Syndrome

\begin{tabular}{|c|c|}
\hline Major Criteria & Minor Criteria \\
\hline Recurrent urticaria $>6$ months & $\begin{array}{l}\text { Biopsy-proven vasculitis } \\
\text { of dermis }\end{array}$ \\
\hline \multirow[t]{5}{*}{ Hypocomplementemia } & $\begin{array}{l}\text { Positive C1q-antibodies } \\
\text { and/or suppressed C1q-level }\end{array}$ \\
\hline & Glomerulonephritis \\
\hline & Arthralgia/arthritis \\
\hline & Ocular inflammation \\
\hline & Recurrent abdominal pain \\
\hline
\end{tabular}

aPatients must fulfill all major criteria and at least 2 minor criteria. The patient we describe presented both 2 major criteria and 3 minor criteria (biopsy-proven vasculitis of dermis, arthralgia, and recurrent abdominal pain). month after withdrawal of omalizumab, the patient presented a stronger exacerbation of diarrhea, abdominal pain, and urticaria (UAS7, 37/42). Omalizumab $300 \mathrm{mg}$ monthly was readministered, leading to complete remission of urticaria (UAS7, 0/42) and gastrointestinal symptoms 1 month later.

To our knowledge, this is the first report of HUVS successfully treated with omalizumab. Our findings contrast with those of a recently reported case in which omalizumab was not effective in improving the skin lesions of a woman affected by HUVS with biopsy-proven membranoproliferative glomerulonephritis [5]. Although more evidence on the efficacy of omalizumab in urticarial vasculitis has been reported [6-8], these are the only 2 reports in the literature that investigate the potential role of omalizumab in HUVS. As HUVS is an uncommon and more severe form of urticarial vasculitis, it is not surprising to observe fewer and contradictory results about the effectiveness of omalizumab administered to treat the disease. We hypothesize that omalizumab is safe and effective in milder forms of HUVS, but not in those involving the kidney and/or the lung, which usually require immunosuppressive drugs [9]. Our case is therefore remarkable, because it shows that withdrawal of omalizumab can lead to immediate exacerbation of the disease, as reported in other cases of chronic spontaneous urticaria and urticarial vasculitis [10]. Clinical trials are strongly recommended to clarify the extent to which omalizumab is effective for selected forms of HUVS and clinical outcomes after its withdrawal.

\section{Funding}

The authors declare that no funding was received for the present study.

\section{Conflicts of Interest}

The authors declare that they have no conflicts of interest.

\section{References}

1. McDuffie FC, Sams WM Jr, Maldonado JE, Andreini PH, Conn DL, Samayoa EA. Hypocomplementemia with cutaneous vasculitis and arthritis: possible immune complex syndrome. Mayo Clin Proc. 1973;48:340-8.

2. Schwartz HR, McDuffie FC, Black LF, Schroeter AL, Conn DL. Hypocomplementemic urticarial vasculitis: association with chronic obstructive pulmonary disease. Mayo Clin Proc. 1982; $57: 231-8$

3. Jachiet M, Flageul B, Deroux A, Le Quellec A, Maurier F, Cordoliani $F$ et al. The clinical spectrum and therapeutic management of hypocomplementemic urticarial vasculitis: data from a French nationwide study of fifty-seven patients. Arthritis Rheumatol. 2015;67:527-34.

4. Alba Marín JC, Martorell Aragones A, Satorre Viejo P, Gastaldo Simeon E. Treatment of Severe Cold-Induced Urticaria in a Child With Omalizumab. J Investig Allergol Clin Immunol. 2015;25:303-4.

5. Aurich S, Simon JC, Treudler R. Omalizumab does not improve skin lesions in a patient with hypocomplementemic urticarial vasculitis syndrome. J Eur Acad Dermatol Venereol. 2017 Mar 8. 
6. Ghazanfar MN, Thomsen SF. Omalizumab for Urticarial Vasculitis: Case Report and Review of the Literature. Case Rep Dermatol Med. 2015;2015:576893.

7. Sussman G, Hébert J, Barron C, Bian J, Caron-Guay RM, Laflamme $S$ et al. Real-life experiences with omalizumab for the treatment of chronic urticaria. Ann Allergy Asthma Immunol. 2014;112:170-4.

8. Díez LS, Tamayo LM, Cardona R. [Omalizumab: therapeutic option in chronic spontaneous urticaria difficult to control with associated vasculitis, report of three cases]. Biomedica. 2013;33:503-12.

9. Enríquez $R$, Sirvent $A E$, Amorós $F$. Crescentic membranoproliferative glomerulonephritis and hypocomplementemic urticarial vasculitis. J Nephrol. 2005; 18:318-22.

10. Kai AC, Flohr C, Grattan CE. Improvement in quality of life impairment followed by relapse with 6-monthly periodic administration of omalizumab for severe treatment-refractory chronic urticaria and urticarial vasculitis. Clin Exp Dermatol. 2014;39:651-2.

Manuscript received June 9, 2017; accepted for publication July 26, 2017.

Fabio Basta

Unit of Allergology, Immunology and Rheumatology

Department of Medicine

Campus Bio-Medico di Roma Via Alvaro del Portillo, 200

00128 Roma, Italy

E-mail: f.basta@unicampus.it

\section{Is Saccharomyces boulardii Really Safe?}

Alves $\mathrm{C}^{1}$, Afonso I ${ }^{2}$, Leiria-Pinto $\mathrm{P}^{1,3}$

${ }^{1}$ Dona Estefânia Hospital, Immunoallergology department, Centro Hospitalar de Lisboa Central, Lisbon, Portugal

${ }^{2}$ Dona Estefânia Hospital, Pediatric Gastroenterology Department, Centro Hospitalar de Lisboa Central, Lisbon, Portugal

${ }^{3}$ CEDOC, Respiratory Research Group, Nova Medical School, Lisbon, Portugal

J Investig Allergol Clin Immunol 2017; Vol. 27(6): 384-386 doi: $10.18176 /$ jiaci.0194

Key words: Saccharomyces boulardii. Hypersensitivity reactions. Food protein-induced enterocolitis syndrome-like.

Palabras clave: Saccharomyces boulardii. Reacciones de hipersensibilidad. Síndrome de enterocolitis inducida por proteínas alimentarias.

Saccharomyces boulardii is a nonpathogenic yeast isolated from the skin of lychees grown in Indochina that has been widely prescribed in the last 30 years for prophylaxis and treatment of bacterial diarrhea $[1,2]$.

Hypersensitivity reactions to $S$ boulardii are rare, and, to the authors' knowledge, only 2 cases have been reported in the literature $[3,4]$.

We present a case of an exclusively breastfed 2-monthold girl, who presented with blood and mucus in stool. Enteritis (viral and bacterial) was excluded, and the mother was advised to begin a dairy-free diet. However, the blood and mucus persisted despite the change to the mother's diet. Rectosigmoidoscopy with biopsy revealed nodular lymphoid hyperplasia and histopathologic evidence of colitis characterized by edematous and hemorrhagic focal areas with eosinophil infiltration (more than 6 per high-power-field) and occasional lymphoid nodes, suggesting a diagnosis of allergic colitis. We therefore reinforced the importance of a dairy-free diet while breastfeeding.

The patient was a healthy, full-term infant delivered by cesarean birth, with normal growth for age.

Blood and mucus persisted in stool, albeit at a lower intensity. At 3 months, the infant began to produce watery stool. $S$ boulardii (UL 250 sachets) was prescribed. The child began to vomit profusely approximately 2 hours after ingestion, with spontaneous resolution within a few hours. Three weeks later, as gastrointestinal symptoms persisted (intermittent watery stools with blood and mucus), she was again treated with $S$ boulardii, 2 hours after which she experienced an episode of uncontrollable vomiting, with severe prostration. She was seen at the emergency department, where she received replacement fluid therapy. The vomiting resolved on the same day, and no other signs of infection were observed.

At that time, she was referred to our Immunoallergology Department. Skin prick tests and specific IgE for milk, casein, $\alpha$-lactalbumin, and $\beta$-lactoglobulin were negative. We diagnosed non-IgE-mediated cow's milk allergy and 
reinforced the importance for both mother and infant of a dairy-free diet. Cow's milk was successfully introduced to the patient's diet at the age of 12 months.

Despite the suspicion of $S$ boulardii hypersensitivity reactions, the parents refused an oral challenge test with this probiotic because their child had tolerated another probiotic (Lactobacillus reuteri).

$S$ boulardii is considered a safe probiotic, although hypersensitivity reactions - while rare - can occur [3,4].

The patient we report presented symptoms indicative of gastrointestinal allergy, such as that occurring in food proteininduced enterocolitis syndrome (FPIES), as in a previously published case of hypersensitivity to $S$ boulardii [3]. We excluded a possible IgE-mediated reaction owing to the absence of associated classic allergic skin or respiratory manifestations and the late onset of the reaction $[4,5]$.

FPIES is a non-IgE-mediated food allergy characterized by profuse vomiting accompanied by pallor and lethargy within 1 to 4 hours (usually 2 hours) after ingestion of the offending food. It also can be followed by diarrhea in 5 to 8 hours in some patients and may last for up to 24 hours after exposure $[5,6]$.

The diagnosis is based on the clinical history, recognition of clinical symptoms, exclusion of other etiologies, and a supervised oral challenge test. Although the challenge test is considered the gold standard, a history of severe, repeated reactions in a patient who becomes asymptomatic after elimination of the suspected culprit is sufficient to make a diagnosis $[5,6]$.

We assessed causality in this suspected adverse drug reaction using the probability scale of Naranjo [7], in which a score of 10 was obtained, indicating a definitive diagnosis. Even though the patient's parents refused an oral challenge test, the Naranjo score supports the link between exposure to $S$ boulardii and FPIES-like reaction [7].

According to international consensus guidelines [5], the major criterion and at least 3 minor criteria must be met for the diagnosis of FPIES. Our patient experienced profuse vomiting 2 hours after ingestion of $S$ boulardii and, when re-exposed, experienced a second episode of repetitive vomiting with extreme lethargy and need for replacement fluid therapy in the emergency department, thus fulfilling the requirements for the diagnosis of FPIES-like reaction. Based on the convincing clinical history with a repeated reaction to the same drug, complete resolution over a matter of hours, and the absence of infectious gastroenteritis, the reaction we describe can be considered an FPIES-like allergic reaction caused by $S$ boulardii.

We hope that our findings raise awareness of possible hypersensitivity reaction to $S$ boulardii.

\section{Funding}

The authors declare that no funding was received for the present study.

\section{Conflicts of Interest}

The authors declare that they have no conflicts of interest.

\section{References}

1. Kelesidis T, Pothoulakis C. Efficacy and safety of the probiotic Saccharomyces boulardii for the prevention and therapy of gastrointestinal disorders. Ther Adv Gastroenterol. 2012;5(2):111-25.

2. Vandenplas $Y$, Brunser 0 , Szajewska $H$. Saccharomyces boulardii in childhood. Eur J Pediatr 2009; 168: 253-65.

3. Hwang JB, Kang KJ, Kang YN, Kim AS. Probiotic gastrointestinal allergic reaction caused by Saccharomyces boulardii. Ann Allergy Asthma Immunol. 2009 Jul;103(1):87-8.

4. Kartal O, Demirel F, Baysan A, Gulec M, Yesillik S, Uyanýk M, et al. An unexpected allergic reaction with Saccharomyces boulardii: a case report. Clin Transl Allergy. 2014;4(Suppl 3):P100.

5. Nowak-Wegrzyn A, Chehade $M$, Groetch $M$, Spergel J, Wood R, Allen K, et al. International consensus guidelines for the diagnosis and management of food proteininduced enterocolitis syndrome. J Allergy Clin Immunol. 2017;139:1111-26.

6. Nowak-Wegrzyn A, Jarocka-Cyrta E, Moschione Castro APB. Food protein-induced enterocolitis syndrome. J Investig Allergol Clin Immunol. 2017; vol.27 (1):1-18.

7. Doherty MJ. Algorithms for assessing the probability of an Adverse Drug Reaction. Respiratory Medicine CME 2, 2009;63-67.

Manuscript received June 5, 2017; accepted for publication July 31, 2017.

Cátia Alves

Serviço de Imunoalergologia Hospital D. Estefânia

Rua Jacinta Marto, 1169-045 Lisboa, Portugal E-mail: catia@catia-alves.net 


\section{Occupational Asthma and Urticaria in a Fishmonger Due to Creatine Kinase, a Cross-Reactive Fish Allergen}

Larco-Rojas $\mathrm{X}^{1}$, González-Gutiérrez $\mathrm{ML}^{1}$, Vázquez-Cortés $\mathrm{S}^{1}$, Bartolomé $\mathrm{B}^{2}$, Pastor-Vargas $\mathrm{C}^{3}$, Fernández-Rivas $\mathrm{M}^{1}$

${ }^{1}$ Allergy Department, Hospital Clínico San Carlos, IdISSC, Madrid, Spain

${ }^{2} R+D$ Department, Roxall, Bilbao, Spain

${ }^{3}$ Immunology Department, IIS-Fundación Jimenez Díaz, UAM, Madrid, Spain

J Investig Allergol Clin Immunol 2017; Vol. 27(6): 386-388 doi: 10.18176/jiaci.0195

Key words: Occupational asthma. Creatine kinase. Cross reactivity. Fish. Urticaria.

Palabras clave: Asma ocupacional. Creatinquinasa. Reactividad cruzada. Pescado. Urticaria.

Fish plays an important role in nutrition and in the world economy. It is one of the main causes of IgE-mediated food allergy and a relevant allergenic source in workplace environments [1]. Occupational allergy most frequently results from direct contact with or inhalation of allergens, which leads to cutaneous or respiratory symptoms. Rhinitis, conjunctivitis, and, less frequently, urticaria may precede asthma symptoms [2].

Parvalbumins are the major allergens involved in fish allergy [3]. Other allergens have been described, but their relevance is not yet well understood; in addition, it has not been established whether the same allergens are involved in occupational fish allergy $[1,2,4]$.

A 29-year-old, nonatopic woman who worked as a fishmonger for 5 years was referred to our allergy department with a 1-month history of generalized hives and pruritus that appeared a few minutes after handling fish at work. She occasionally experienced mild dyspnea but denied cough or wheezing. Her condition improved on weekends and holidays. She tolerated fish and shellfish but stopped eating them once she started experiencing symptoms with fish at work.

We performed skin prick test (SPTs) with commercial extracts of tuna, sardine, cod, sole, hake, and whiff (Bial Aristegui). We also performed SPTs with the most prevalent aeroallergens (ALK-Abelló) in our area (dust mites, fungi, cockroach, cat and dog dander, pollens [grass, cypress, plane tree, olive, Russian thistle, mugwort, and plantain]), with seafood extracts (LETI) (shrimp, oyster, clam, squid, and mussel), and with the fish parasite Anisakis (ALK-Abelló). SPTs were only positive to tuna, sardine, cod, sole, hake, whiff, shrimp, and Dermatophagoides pteronyssinus.

Prick-prick tests were also performed with raw and cooked hake, sole, and tuna, and the results were positive to all 3 types of fish, although only when tested raw.

Baseline spirometry values were normal: FVC, 3.30 L (101.8\%); $\mathrm{FEV}_{1}, 2.62 \mathrm{~L}$ (93.3\%); and $\mathrm{FEV}_{1} / \mathrm{FVC}, 79.53 \%$. The result of a bronchodilator test was negative. The FeNO level was $7 \mathrm{ppb}$.

Rubbing tests with raw hake and tuna were carried out on the volar aspect of the forearm on 2 separate days with $\mathrm{FEV}_{1}$ being monitored by spirometry. Although no local skin reactions were observed, generalized pruritus and a micropapular rash appeared on the patient's neckline on both days a few minutes after exposure, together with a decrease in $\mathrm{FEV}_{1}$ of $15 \%$ and $16 \%$ over baseline, respectively.

\section{A. Immunoblotting}

B. Immunoblotting inhibition

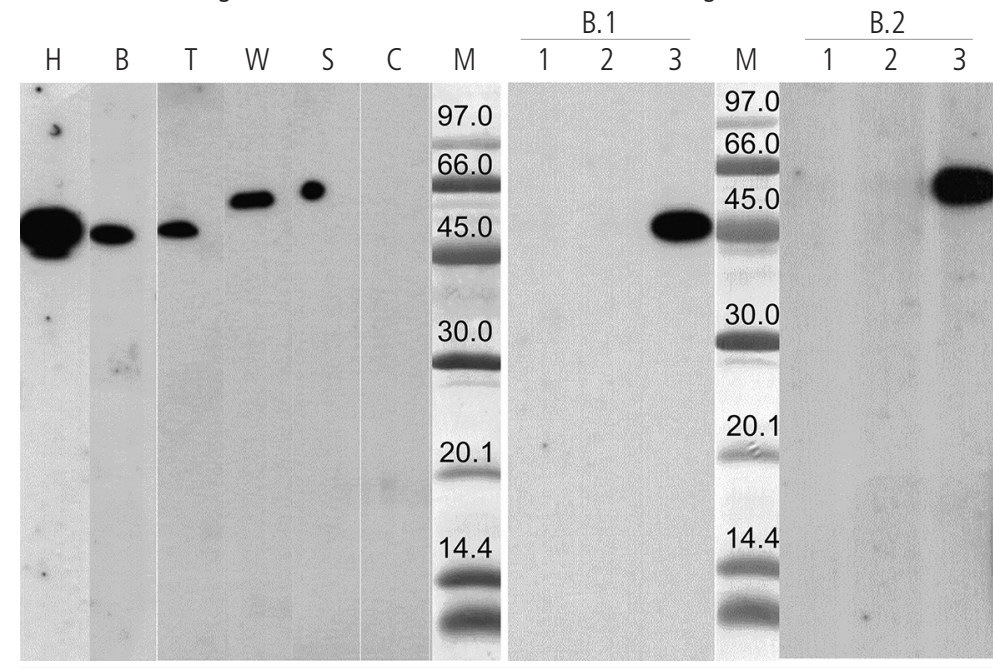

C. Effect of simulated gastric fluid on hake extract

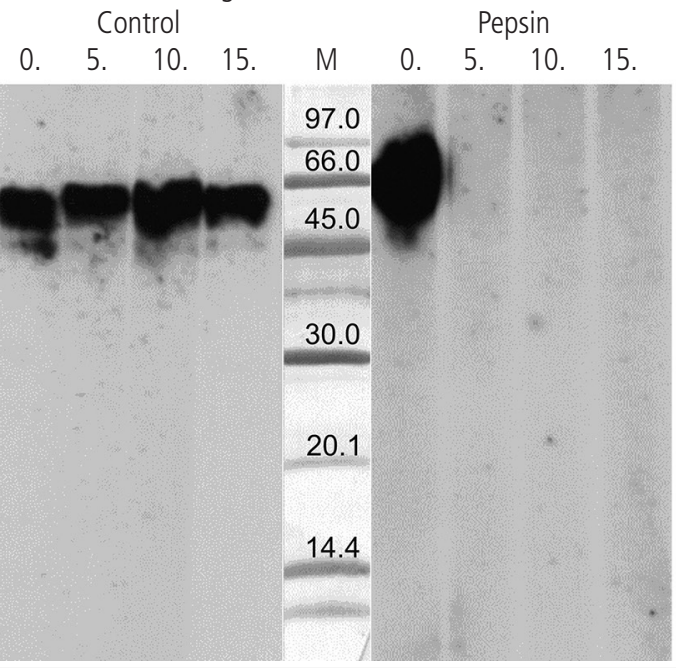

Figure. A, lgE immunoblotting without B-mercaptoethanol (nonreducing conditions). H indicates hake; B, black halibut; T, trout; W, whiff; $S$, sole; C, control (represents all controls for all the fish since they were similar). B, IgE immunoblotting inhibition. Panel B.1: black halibut in solid phase. Inhibitors: 1, black halibut; 2, hake; 3, lamb (negative control). Panel B.2: whiff in solid phase. Inhibitors: 1, whiff; 2, hake; 3, lamb (negative control). C, Effect of simulated gastric fluid on hake extract (SDS-PAGE) at 0 (baseline), 5, 10, and 15 minutes. Control: nontreated extract. Pepsin: pepsin (0.32\% wt/vol) treated extract. M indicates molecular weight markers $(\mathrm{kDa})$. 
Total IgE, baseline serum tryptase, and specific $\operatorname{IgE}$ ( $\operatorname{sgE})$ to rCyp c1 (carp parvalbumin), rPen a1 (shrimp tropomyosin), salmon, tuna, cod, mackerel, trout, sole, hake, shrimp, and $D$ pteronyssinus were determined (ImmunoCAP, Thermo Fisher Scientific). Total serum IgE was $85.3 \mathrm{kU} / \mathrm{L}$, and tryptase $3.2 \mu \mathrm{g} / \mathrm{L}$. Serum $\mathrm{sIgE}$ was positive to sole $\left(0.79 \mathrm{kU}_{\mathrm{A}} / \mathrm{L}\right)$ and hake $\left(9.95 \mathrm{kU}_{\mathrm{A}} / \mathrm{L}\right)$, but no $\operatorname{sigE}$ was detected to $\mathrm{rCyp}$ c 1 , salmon, tuna, cod, mackerel, trout, rPen a 1, shrimp, Anisakis, or $D$ pteronyssinus $\left(\right.$ all $\left.<0.10 \mathrm{kU}_{\mathrm{A}} / \mathrm{L}\right)$.

In order to investigate the allergens involved, extracts of hake, sardine, black halibut, trout, whiff, and sole were prepared by homogenization in phosphate-buffered saline (15\% wt/vol) and analyzed using SDS-PAGE, followed by IgE immunoblotting under nonreducing conditions [5]. The results revealed an IgE binding band between 45 and $66 \mathrm{kDa}$ in all fish tested (Figure).

Immunoblotting inhibition assays were performed [5]. Immunoblotting with black halibut extract was inhibited with black halibut and hake, and immunoblotting with whiff extract was inhibited with whiff and hake. For the assays, the patient's serum was incubated for 16 hours at $4^{\circ} \mathrm{C}$ with 1 $\mathrm{mg} / \mathrm{L}$ of the inhibitor. Complete inhibition of the IgE binding band was observed with all the fish extracts, but not with lamb $(1 \mathrm{mg} / \mathrm{mL}$ ), which was used as a negative control (Figure, panel B, B.1 and B.2).

A simulated gastric acid digestion assay of the hake extract was performed with a solution of $100 \mathrm{mmol} / \mathrm{L}$ hydrochloride containing $0.32 \% \mathrm{wt} / \mathrm{vol}$ of pepsin A (Sigma Aldrich Life Sciences [Merck]) and $\mathrm{pH} 1.2$ [6]. Aliquots of this solution were withdrawn at 5, 10, and 15 minutes and subsequently subjected to immunoblotting, which showed that the $\operatorname{IgE}$ binding band disappeared with the simulated digestion (Figure, panel C).

Taking into account the aforementioned results and in order to normalize the patient's diet, an oral challenge test was performed with cooked hake. The fish was well tolerated.

Proteins were identified using mass spectrometry (MS) and/or MS/MS [7]. The IgE-binding protein band was cut from the Coomassie blue-stained SDS-PAGE gel. After alkylation and trypsin digestion, the resulting peptide mixture was analyzed using matrix-assisted laser desorption/ionization time-of-flight (MALDI-TOF) MS, and the peptide sequences obtained were SFLVWVNEEDHIR, DWPDARGIWHNDDK, and GIWHNDDKSFLVWVNEEDHIR. Protein identification performed by searching a nonredundant protein sequence database (National Center for Biotechnology Information) showed that the protein was creatine kinase (CK).

CK belongs to the ATP:guanido phosphotransferase family and plays a key role in regulating the metabolism of adenosine triphosphate, which is the primary source of energy in animals [8-10]. CK is abundant in fish muscle and belongs to the same guanidine family of kinases as the crustacean allergen arginine kinase, which is a highly crossreactive nonvertebrate panallergen [10] and an occupational shellfish allergen [2]. CK shares $45 \%$ identical and 55\% similar subunits with arginine kinase [9], thus potentially explaining the (clinically irrelevant) SPT reactivity to shrimp and mites in this case. CK is a thermolabile food allergen [9], as reflected by the negative SPT result and good oral tolerance of cooked fish, which is also favored by its lability to pepsin digestion.

The lability of CK to heat and proteolytic digestion may explain the occupational onset of fish allergy in the patient we report, who probably became sensitized through exposure to raw fish via the skin and/or inhalation in the workplace.

In summary, we report a patient with occupational urticaria and asthma to fish due to sensitization to CK. To our knowledge, this is the first case in which CK has been shown to be a cross-reactive allergen in occupational fish allergy.

\section{Funding}

The authors declare that no funding was received for the present study.

\section{Conflicts of Interest}

The authors declare that they have no conflicts of interest.

\section{Previous Presentations}

This case report was presented as a poster and oral presentation at the European Congress of the EAACI held in Barcelona, June 2015 and was awarded second prize in the junior member Oral Case report session.

\section{References}

1. Sharp MF, Lopata AL. Fish allergy: in review. Clin Rev Allergy Immunol. 2014;46:258-71.

2. Lopata AL, Jeebhay MF. Airborne seafood allergens as a cause of occupational allergy and asthma. Curr Allergy Asthma Rep. 2013;13:288-97.

3. Griesmeier $U$, Vázquez-Cortés $S$, Bublin $M$, Radauer $C, M a$ $Y$, Briza $P$, et al. Expression levels of parvalbumins determine allergenicity of fish species. Allergy. 2010;65:191-8.

4. Jeebhay MF, Robins TG, Lehrer SB, Lopata AL. Occupational seafood allergy: A review. Occup Environ Med, BMJ. 2001;58:553-62.

5. Pérez-Calderón R, Gonzalo-Garijo MÁ, Rodríguez-Velasco FJ, Sánchez-Vega S, Bartolomé-Zavala B. Occupational respiratory allergy in peach crop workers. Allergy. 2017;72:1556-64.

6. Benito C, González-Mancebo E, Alonso Díaz de Durana MD, Tolón RM, Fernández Rivas M. Identification of a 75 globulin as a novel coconut allergen. Ann Allergy Asthma Immunol. 2007;98:580-4.

7. Pastor C, Cuesta-Herranz J, Cases B, Pérez-Gordo M, Figueredo

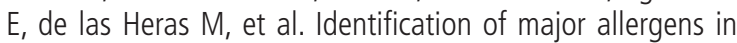
watermelon. Int Arch Allergy Immunol. 2009;149:291-8.

8. Liu R, Krishnan HB, Xue W, Liu C. Characterization of allergens isolated from the freshwater fish blunt snout bream (Megalobrama amblycephala). J Agric Food Chem. 2011;59:458-63.

9. Rosmilah $M$, Shahnaz $M$, Meinir J, Masita A, Noormalin A, Jamaluddin M. Identification of parvalbumin and two new thermolabile major allergens of Thunnus tonggol using a proteomics approach. Int Arch Allergy Immunol. 2013;162:299-309. 
10. Tomm JM, Van Do T, Jende C, Simon JC, Treudler R, Von Bergen $M$, et al. Identification of new potential allergens from Nile Perch (Lates niloticus) and cod (Gadus morhua). J Investig Allergol Clin Immunol. 2013;23:159-67.

- Manuscript received June 2, 2017; accepted for publication August 24, 2017.

$$
\begin{array}{r}
\text { Montserrat Fernández-Rivas } \\
\text { Allergy Department } \\
\text { Hospital Clínico San Carlos } \\
\text { IdISSC } \\
\text { C/ Prof. Martín Lagos s/n } \\
28040 \text { Madrid } \\
\text { Spain }
\end{array}
$$

E-mail: mariamontserrat.fernandez@salud.madrid.org

\section{Different Skin Prick Test Sensitization Patterns Do Not Influence the Response to Omalizumab in Severe Asthma}

Sposato $\mathrm{B}^{1}$, Scalese $\mathrm{M}^{2}$, Milanese $\mathrm{M}^{3}$, Masieri $\mathrm{S}^{4}$, Cavaliere $\mathrm{C}^{4}$, Latorre $\mathrm{M}^{5}$, Scichilone $\mathrm{N}^{6}$, Matucci $\mathrm{A}^{7}$, Vultaggio $\mathrm{A}^{7}$, Ricci $\mathrm{A}^{8}$, Cresti $\mathrm{A}^{9}$, Paggiaro $\mathrm{PL}^{5}$

${ }^{1}$ Pneumology Department, Misericordia Hospital, Grosseto, Italy ${ }^{2}$ Institute of Clinical Phisiology, CNR, Pisa, Italy

${ }^{3}$ Pneumology Department, S.Corona Hospital, Pietra Ligure, Italy ${ }^{4}$ Otorhinolaryngology Clinic, Policlinico Umberto I, "Sapienza" University, Rome, Italy

${ }^{5}$ Cardio Thoracic and Vascular Department, Pathophysiology Unit, University of Pisa, Pisa, Italy

${ }^{6}$ DIMPEFINU, Unit of Pneumology and Medicine, University of Palermo, Palermo, Italy

${ }^{7}$ Immunoallergology Unit, Department of Medicine and Geriatric, AOU Careggi, Florence, Italy

${ }^{8}$ Division of Pneumology, Department of Clinical and Molecular Medicine, Sapienza University of Rome, AOU Sant'Andrea, Rome, Italy

${ }^{9}$ Cardiology Department, Misericordia Hospital, Grosseto, Italy

J Investig Allergol Clin Immunol 2017; Vol. 27(6): 388-391 doi: 10.18176/jiaci.0196

Key words: Omalizumab. Severe asthma. Pollen sensitized. Effectiveness. Real-life.

Palabras clave: Omalizumab. Asma severa. Sensibilización a polen. Eficacia. Vida real.

Omalizumab (Xolair) is a monoclonal antibody that is recommended as add-on treatment in patients with severe persistent uncontrolled allergic asthma. It is currently prescribed in severe asthmatics sensitized to perennial allergens, which are thought to be responsible for the persistent status of inflamed airways. This is the case for dust mite, which has been associated with severe asthma [1]. However, other allergens can cause perennial allergy-like conditions and therefore - albeit with reduced prevalencesevere asthma [2]. In this context, pollen allergens such as those of Parietaria have a long pollination period in some Mediterranean areas, thus leading them to resemble perennial allergens [2,3]. Furthermore, polysensitized individuals (ie, sensitized to several pollens with different seasonal pollinations) may also experience persistent asthma [1]. Finally, cross-reactivity between various pollen allergens (including food allergens) and sensitization to profilin may induce persistent symptoms for a large part of the year [4]. Exposure only to seasonal allergens may induce the so-called minimal persistent airway inflammation, with symptoms that occur outside the pollen season [5]. To the best of our knowledge, studies on the effectiveness of omalizumab have only included asthmatics who are mono- and polysensitized to dust mite. Therefore, in a real-world setting, we explored 
whether differences in skin prick test sensitization (in particular pollen sensitization) influence the response to omalizumab in severe asthma.

We retrospectively evaluated 304 patients with severe persistent allergic asthma. All patients were treated with omalizumab because they were poorly controlled with combinations of inhaled corticosteroids (ICS), long-acting $\beta 2$-agonists (LABA), and montelukast. The patients had been in treatment with anti-IgE for at least 6 months (range, 6-120 months). On the basis of skin prick test results for common aeroallergens (performed before initiation of treatment), the population was divided into 3 groups. The first group included patients who were monosensitized to Dermatophagoides species (mite-monosensitized group, $\mathrm{n}=83 ; 35$ males; mean [SD] age, 54 [14] years); the second group consisted of patients who were polysensitized to Dermatophagoides species and other allergens such as pollens, molds, and dog/cat dander (mite-polysensitized group, $\mathrm{n}=193 ; 56$ males; mean age, 52 [13] years); the third group included patients who were sensitized to a single pollen allergen (mainly Parietaria) or other pollens, mold, and dog/cat dander (pollen sensitization group) ( $\mathrm{n}=28 ; 14$ males; mean age, 49.6 [16] years). The results of treatment with omalizumab were compared between the 3 groups. The outcomes recorded were $\mathrm{FEV}_{1} \%$, exacerbations, Asthma Control Test (ACT) score, use of short-acting $ß$-agonists (SABA), asthma control levels, step-up/down of treatment, and ICS doses.

All anthropometric and clinical characteristics were similar in the 3 groups (age, sex, body mass index, smoking habit, comorbidities, and type of treatment). Total IgE levels, omalizumab dose, and age of asthma onset in the mitemonosensitized group (321.7 [243.2] IU/mL, 300 [300-600] mg, 34 [18] years, respectively) were different $(P<.05)$ when compared with the mite-polysensitized group (423.8 [319] IU/ $\mathrm{mL}, 450$ [300-672] mg, 25 [14] years, respectively), whereas no differences were found in comparison with the pollen sensitization group (377 [312] IU/mL, 450 [300-600] mg, 28 [16] years, respectively).
A
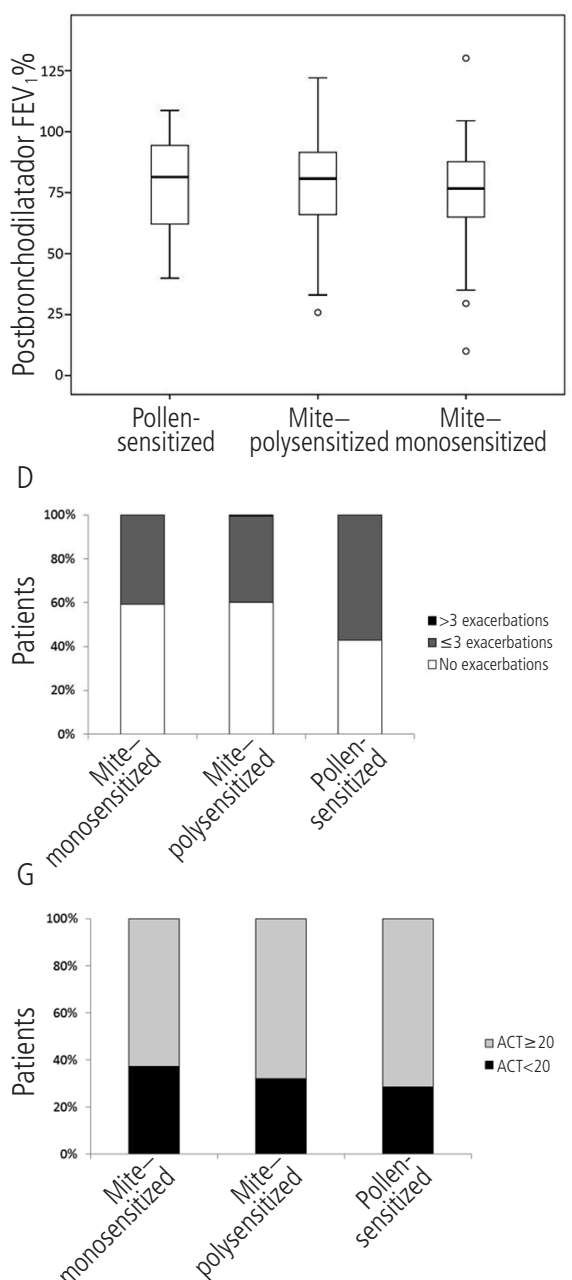

B

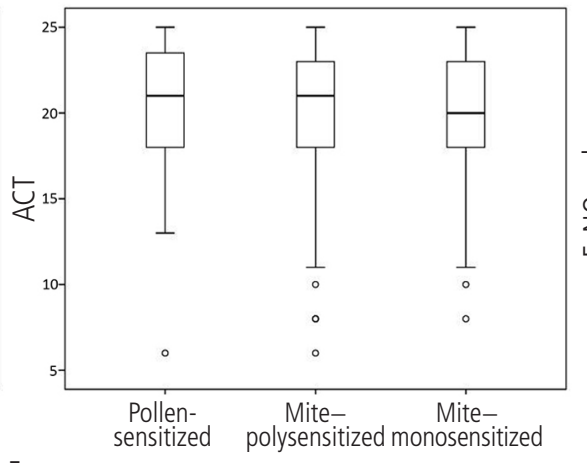

E

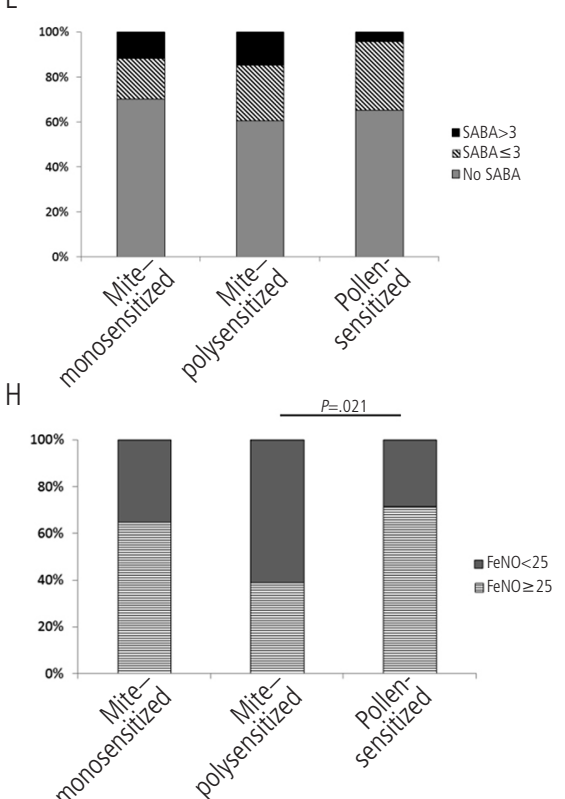

C

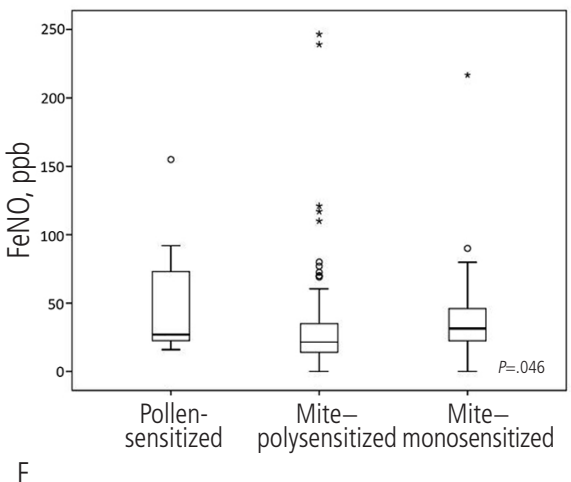

F
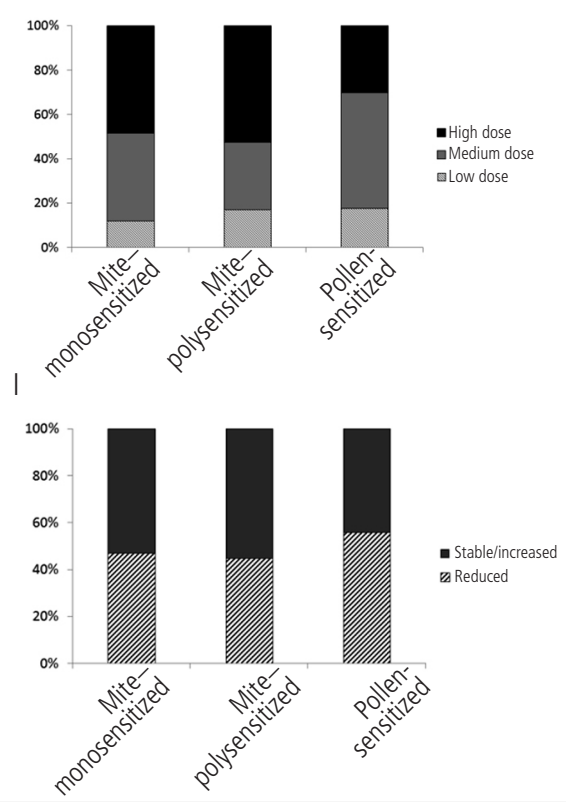

Figure. Results obtained after treatment with omalizumab in the 3 different groups.

Median values for FEV $(A)$, Asthma Control Test (B), and FeNO (C). Percentages of patients with different numbers of exacerbations (D) (in the last year of omalizumab treatment), use of SABAs (E) (in the last month of omalizumab treatment), and different doses of ICS taken at the end of omalizumab treatment (F). Percentages of patients with ACT $<$ or $>20(\mathrm{G})$, FeNO $<$ and $>25 \mathrm{ppb}(\mathrm{H})$, and with a step-down or step-up of other medications (excluding omalizumab) (I). 
Postbronchodilator FEV1\%, ACT score, number of exacerbations, FeNO, ICS dose, use of SABAs, and number of patients whose dose was reduced after treatment with omalizumab (because their asthma had improved) were similar in all groups (Figure). Furthermore, the number of patients with different GINA control levels was similar in the 3 groups, as was the proportion of patients on treatment with ICS, LABAs, long-acting muscarinic antagonists, and oral corticosteroids (data not shown). Only FeNO values were lower in the mite-polysensitized group (21.5 [14-35]) than in the mite-monosensitized group (31.5 [22-52]) and pollen-sensitized group (27 [19-92] (Figure, C) $(P<.05)$. In addition, the percentage of patients with FeNO $>25 \mathrm{ppb}$ was lower in the mite-polysensitized group $(38.8 \%)$ than in the pollen-sensitized group $(71.4 \% ; P=.021)$. Linear regression models $(\beta)$ adjusted for all confounding variables (age, $\mathrm{FEV}_{1}$, body mass index, various sensitizations, IgE values, omalizumab doses, comorbidities, smoking habits, age at asthma onset, treatments other than omalizumab, daily dose of ICS, use of oral corticosteroids and montelukast, duration of treatment with omalizumab, aspirin intolerance, and shortacting bronchodilator responses) showed that sensitization to pollens (nonmite group) and to dust mite plus other allergens (the mite-polysensitized group, compared with the mitemonosensitized group) was not associated with any changes in postbronchodilator $\mathrm{FEV}_{1} \%$ (2.69 [-6.42 to 11.81$], P=.56$; 4.95 [ -0.94 to 10.84 ], $P=.099$, respectively), FeNO (14.87 [ -19.03 to 48.78$], P=.387 ;-6.39$ [ -23.39 to 10.6$], P=.458$, respectively), and ACT ( -0.297 [ -1.9 to 1.3$], P=.716 ; 0.26$ [ -0.703 to 1.22$], P=.596$, respectively) after treatment with omalizumab. In addition, these 2 categories of sensitization (when compared with the mite-monosensitized group) were not risk factors (logistic and multinomial models when appropriate) for having an ACT >20 (2.091 [0.636-6.867]; $1.763[0.893-3.478])$, for not using SABAs (1.241 [0.449$3.429] ; 1.566$ [0.843-2.908]), or for receiving a reduced dose of ICS (1.579 [0.428-5.831]; 1.510 [0.653-3.494]). Moreover, these 2 types of sensitizations were not risk factors for exacerbations (1.999 [0.791-5.054]; 0.823 [0.477-1.421]) or a step down of treatment (1.365 [0.560-3.327]; 0.908 [0.5281.560]). A lower risk factor for a FeNO value $>25 \mathrm{ppb}$ was detected only in the mite-polysensitized group $(0.349$ [0.148$0.821] ; P=.016)$.

These results suggest that the different types of allergen sensitization do not affect the response to omalizumab. Omalizumab improves all asthma outcomes, even in pollensensitized patients with persistent asthma, as observed in patients sensitized to dust mite. Omalizumab binds to free IgE, which lowers free IgE levels and causes down-regulation of FceRI receptors in basophils and mast cells. This can lead to underproduction of proinflammatory cytokines [6-8]. Therefore, the blocking of IgE by omalizumab can also be effective in patients with persistent asthma and seasonal sensitization [9], as well as in other IgE-mediated allergic diseases such as atopic dermatitis, rhinitis, food allergy, and even in asthmachronic obstructive pulmonary disease overlap syndrome [7]. According to our study, FeNO values were lower in the mite-polysensitized group, whereas total serum IgE rates were higher. Omalizumab probably reduces airway inflammation better when IgE levels are higher, a situation that is particularly likely in polysensitized patients [10], whose asthma may be more severe. In conclusion, the effectiveness of omalizumab does not change with allergen sensitization, thus providing evidence for more extensive use of the drug in the most severe forms of asthma.

\section{Funding}

The authors declare that no funding was received for the present study.

\section{Conflicts of Interest}

The authors declare that they have no conflicts of interest.

\section{References}

1. Sylvestre L, Jégu J, Metz-Favre C, Barnig C, Qi S, de Blay F. Component-Based Allergen-Microarray: Der p 2 and Der $f$ Dust Mite Sensitization Is More Common in Patients With Severe Asthma. J Investig Allergol Clin Immunol. 2016;26:141-3.

2. Sala-Cunill A, Bartra J, Dalmau G, Tella R, Botey E, Raga E, et al. Prevalence of asthma and severity of allergic rhinitis comparing 2 perennial allergens: house dust mites and Parietaria judaica pollen. J Investig Allergol Clin Immunol. 2013;23:145-51.

3. Ariano R, Cecchi L, Voltolini S, Quercia O, Scopano E, Ciprandi G; AAllTO Study group on Pollen Allergy. Parietaria pollination duration: myth or fact? Eur Ann Allergy Clin Immunol. 2017:49:6-10.

4. Rodríguez Del Río P, Díaz-Perales A, Sánchez-García S, Escudero C, Ibáñez MD, Méndez-Brea P, Barber D. Profilin, a change in the paradigm. J Investig Allergol Clin Immunol. 2017 Aug 1:0. doi: 10.18176/jiaci.0193. [Epub ahead of print]

5. Panzner $P$, Malkusová I, Vachová $M$, Liška $M$, Brodská $P$, Růžičková 0 , et al. Bronchial in-flammation in seasonal allergic rhinitis with or without asthma in relation to natural expo-sure to pollen allergens. Allergol Immunopathol (Madr). 2015;43:3-9.

6. Pennington LF, Tarchevskaya S, Brigger D, Sathiyamoorthy K, Graham MT, Nadeau KC, et al. Structural basis of omalizumab therapy and omalizumab-mediated $\operatorname{lgE}$ exchange. Nat Commun. 2016;7:11610.

7. Stokes JR, CasaleTB. The use of anti-lgE therapy beyond allergic asthma. J Allergy Clin Immunol Pract. 2015;3:162-6.

8. Humbert $M$, Busse W, Hanania NA, Lowe PJ, Canvin J, Erpenbeck VJ, et al. Omalizumab in asthma: an update on recent developments. J Allergy Clin Immunol Pract. 2014;2:525-36.

9. Kopp MV, Hamelmann E, Zielen S, Kamin W, Bergmann KC, Sieder C, et al.; DUAL study group. Combination of omalizumab and specific immunotherapy is superior to immuno-therapy in patients with seasonal allergic rhinoconjunctivitis and co-morbid seasonal allergic asthma. Clin Exp Allergy. 2009;39:271-9.

10. De Marco R, Marcon A, Jarvis D, Accordini S, Almar E, Bugiani $M$, et al.; European Community Respiratory Health Survey 
Therapy Group. Prognostic factors of asthma severity: a 9-year international prospective cohort study. J Allergy Clin Immunol. 2006; 117:1249-56

Manuscript received July 23, 2017; accepted for publication August 4, 2017.

Bruno Sposato

U.O. Pneumologia, Azienda Ospedaliera "Misericordia"

Via Senese 161

58100 GROSSETO, Italy

E-mail: bsposat@tin.it

\section{IgE-Binding Aldolases From Artemia and Mysis Species Causing Respiratory Allergy to Aquarium Fish Food}

Ceballos $\mathrm{M}^{1}$, De Castro $\mathrm{C}^{2}$, Fonseca Gabriel $\mathrm{M}^{1}$, Postigo $\mathrm{I}^{1}$, Martinez $\mathbf{J}^{1}$

${ }^{I}$ Department of Immunology, Microbiology and Parasitology, Faculty of Pharmacy and Laboratory of Parasitology and Allergy, Lascaray Research Centre, University of the Basque Country, Vitoria, Spain ${ }^{2}$ Allergy Department, ADESLAS Medical Center, Córdoba, Spain

J Investig Allergol Clin Immunol 2017; Vol. 27(6): 391-393 doi: $10.18176 /$ jiaci.0198

Key words: Allergen microarray. Allergen-specific IgE. Cross-reactivity. Occupational asthma. Skin prick test.

Palabras clave: Microarray. IgE alérgeno-específica. Reactividad cruzada. Asma ocupacional. Pruebas cutáneas.

Aquarium fish food has been recognized as a source of allergenic proteins and a relevant cause of occupational allergy [1]. IgE-mediated respiratory diseases have been reported at work and at home during handling of aquarium fish food as a consequence of exposure to aeroallergens from the dried arthropod species contained in the product [1-3].

We report the case of a 49-year-old man who reported allergic symptoms, including rhinoconjunctivitis, ocular angioedema, and asthma, after feeding the fish in his aquarium. The patient gave his written informed consent to participate in the study, and a sample of his serum was used for specific $\operatorname{IgE}(\mathrm{s} \operatorname{IgE}$ ) detection assays. A comprehensive picture of the individual's sensitization profile was obtained using the allergen microarray immunoassay (ImmunoCAP ISAC, Thermo Fisher Scientific), which contains 112 pure allergen components from several clinically relevant allergen sources. Relevant sIgE results ( $>0.3$ ISU) were recorded for allergens from avocado (rAna o 2, 1.0ISU), London plane tree (nPla a 2, 1.3 ISU), olive tree (nOle e 1, 0.4 ISU), latex ( $\mathrm{rHev}$ b 1, 0.4 ISU and rHev b 6, 0.4 ISU), and peach (nPru p 3, 0.6 ISU), thus demonstrating that this atopic patient was sensitized to multiple plant allergens.

During the last decade, the application of genomics and proteomics in allergen research has enabled the development of innovative assays for component-resolved diagnosis (CRD), which provides a more targeted and informative diagnosis of allergy. However, commercially available assays for CRD of sensitization to IgE cannot yet fully explain some clinical cases, particularly among the crustacean-allergic population [4]. The array of allergen components in the ImmunoCAP ISAC technology used in the present study includes 3 allergenic proteins from crustacean species (the tropomyosins rPen a 1 from Farfantepenaeus aztecus, nPen i 1 from Fenneropenaeus indicus, and nPen $\mathrm{m} 1$ from Penaeus monodon) and 2 allergenic parvalbumins from carp and cod (rCyp c 1 [Cyprinus carpio] and rGad c 1 [Gadus callarias]). 
In the present case, the patient's serum did not react to any of these proteins, thus suggesting that more research is needed to accurately identify the allergenic proteins and sources causing the clinical symptoms. The patient's clinical history led us to assume that the allergy symptoms were caused by IgE against specific allergenic components of the aquarium fish food. Therefore, we studied the patient's sensitization profile by preparing protein extracts from the main constituents (Artemia, Mysis, microplankton, Cyclops, red plankton, Daphnia, Rotifers, bloodworms, and Artemia roe [Ocean Nutrition, Belgium]). Skin prick tests (SPTs) using the laboratoryextracted proteins $(100 \mu \mathrm{g}$ protein/mL extract) were carried out by a trained allergist. SPTs were only positive to Artemia, Mysis, and bloodworms. One milligram (total protein) of all extracts was biotin-labeled (Biotin Protein Labeling Kit, Roche Applied Science), coupled to streptavidin ImmunoCAPs (Thermo Fisher Scientific), and then used to measure sIgE levels. Specific IgE testing with the protein extracts yielded the following results $\left(\mathrm{kU}_{\mathrm{A}} / \mathrm{L}\right)$ : Artemia, 5.18; Mysis, 5.31; microplankton, 0.85; bloodworms, 0.70; Artemia roe, 0.68; Cyclops, 0.58; red plankton, 0.55; Daphnia, $<0.35$; and Rotifers, $<0.35$. In fact, data from the SPT and ImmunoCAP

A

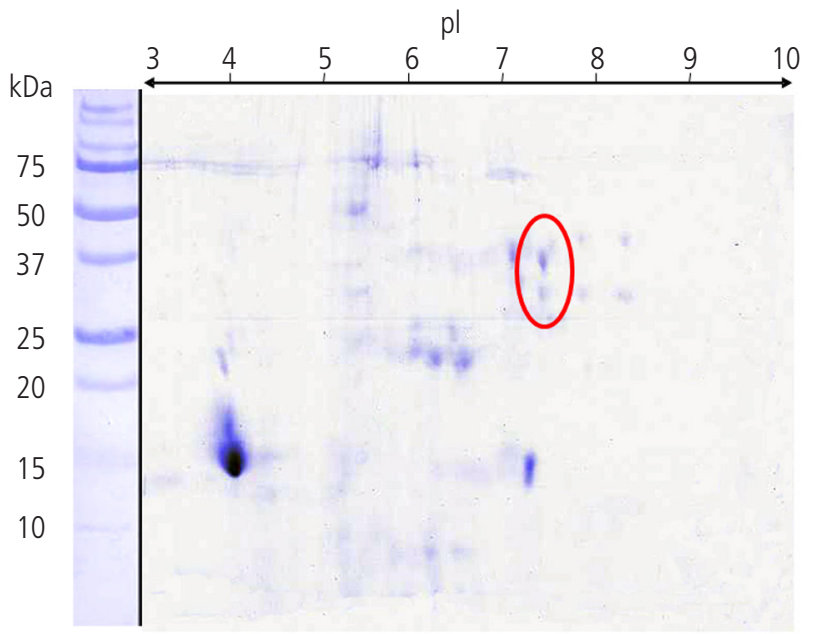

B

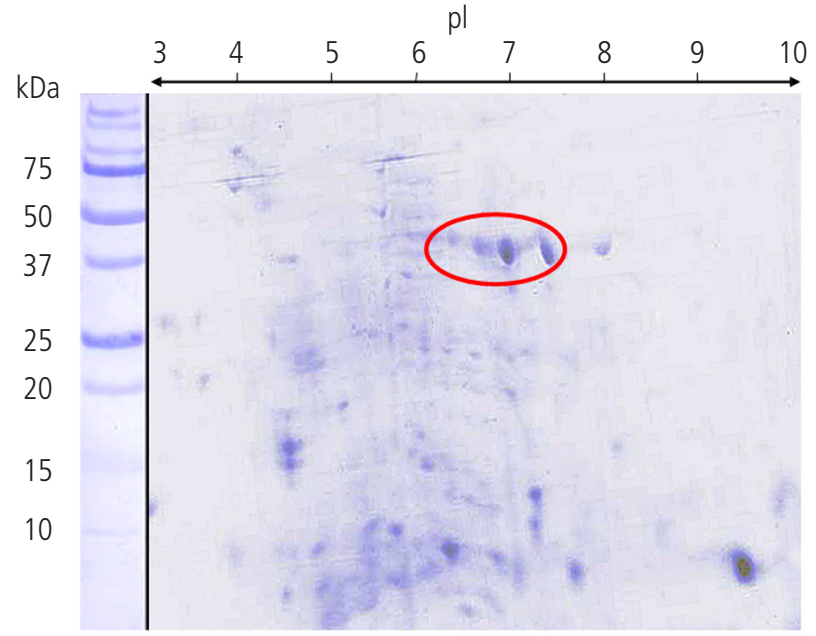

assays were very consistent using both methodologies, with strong positive results for Artemia and Mysis extracts. Therefore, protein extracts from both species were analyzed using SDS-PAGE and IgE immunoblotting with the patient's serum. SDS-PAGE based on Coomassie-stained gels exhibited several protein bands with some smeared zones (data not shown). To improve the resolution of the individual proteins and to enable identification of the allergenic proteins involved in the present case, we also performed 2D electrophoresis and 2D electrophoresis IgE immunoblotting. Serum from a healthy donor showing negative results $\left(<0.35 \mathrm{kU}_{\mathrm{A}} / \mathrm{L}\right)$ to all extracts was used as a negative control. No spots were visualized for the negative control serum. Protein spots corresponding to the IgE-binding proteins of both Artemia and Mysis extracts were excised from 2D IgE immunoblotting using patient serum and sent to the Proteomics Unit of the Spanish National Center for Biotechnology, Madrid, Spain for identification using MALDI-TOF/TOF (Figure). In the case of Artemia, because all 4 IgE-binding protein spots presented the same molecular weight $(39 \mathrm{kDa})$ but different isoelectric points, they likely represent 4 isotypes of the same protein. Indeed, all 4 IgE-binding proteins were identified by MALDI as the
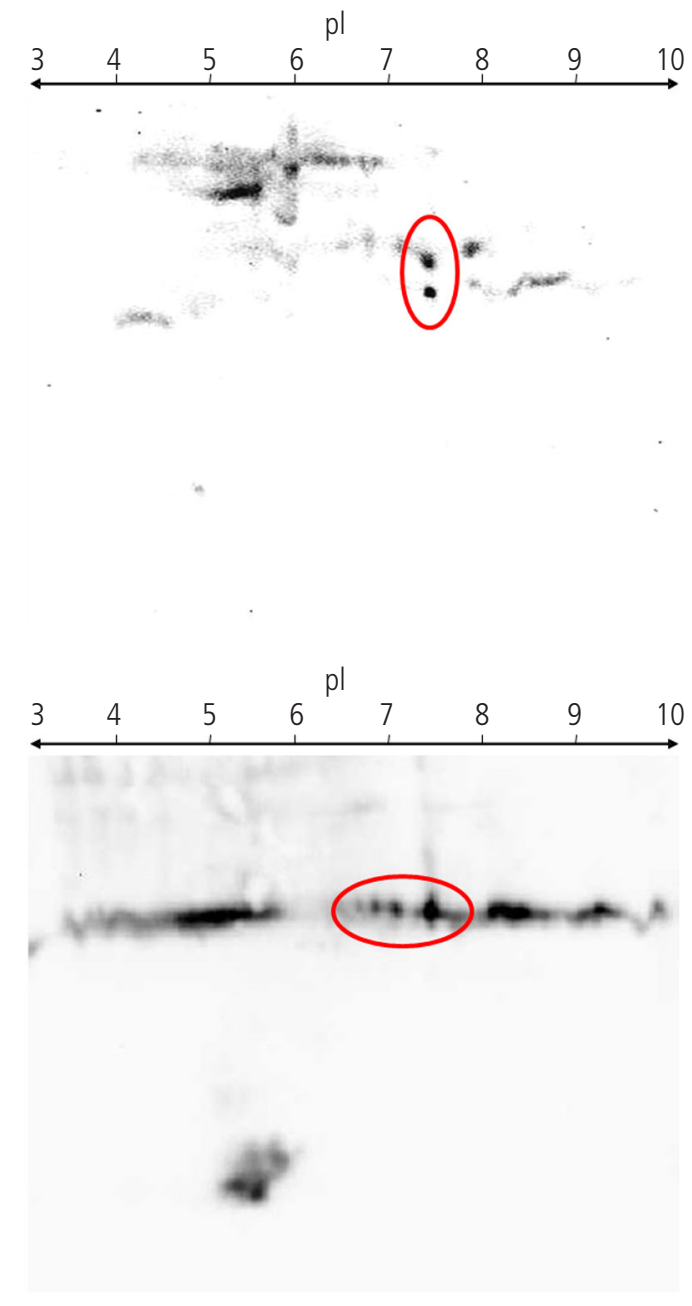

Figure. Two-dimensional electrophoresis and respective lgE-immunoblotting of (A) Mysis and (B) Artemia crude extracts. Immunoblotting was performed using the patient's serum. pl indicates isoelectric point. 
same protein, a fructose 1,6-bisphosphate aldolase presenting the highest peptide sequence homology score to a protein described for Artemia franciscana (GenBank accession number ACH81781.1). In the case of Mysis, the 2 IgE-reactive protein spots highlighted in the Figure were also identified as fructose 1,6-bisphosphate aldolase and were homologous with the protein sequence of Haliotis diversicolor (GenBank accession number ABY87348.1), the most similar homologous protein identified to date and registered in the NCBI database.

Fish aldolases have been identified as relevant new fish allergens, and some authors support the inclusion of aldolases in the diagnosis of fish allergy [5]. Because a significant level of interspecies cross-reactivity has been reported for aldolases [5], FASTA sequences of both identified homologous proteins were compared with those in the Structural Database of Allergenic Proteins (SDAP). Both present significant homology (for ACH81781.1, Blast e-value, 6e-119; \% query cover, 100; \% identity, 70; SDAP e-score, 3e-76; and for ABY87348.1, Blast e-value, 4e-114; \% query cover, 100; \% identity, 65; SDAP e-score, 2.2e-63) with Sal s 3 (GenBank accession number B5DGM7.1) from Salmo salar (Atlantic salmon). Given that cross-reactivity between aeroallergens and food allergens is an increasingly reported health issue [6,7], it would be prudent to search for sensitization to other fish aldolases and to warn the patient about an eventual further reaction to food, in particular upon ingestion of salmon and crustaceans. For instance, an aldolase was also recently identified as a heat-labile IgE-binding protein from black tiger prawn, suggesting that aldolase-sensitized patients probably tolerate well-cooked fish and crustaceans [8].

In summary, our results indicate that IgE-reactive aldolases identified from Artemia and Mysis species were responsible for sensitization to aquarium fish food, which induced the allergic symptoms in a patient involved in fishkeeping. Both Artemia and Mysis belong to the crustacean subphylum [9] and are commercialized worldwide for fishkeeping as constituents of aquarium fish food. In this regard, and based on the findings presented here, the patient should be informed about the potential risks of handling fish food with Mysis and Artemia species as constituents. Therefore, in addition to oral antihistamines for reducing some seasonal mild allergic manifestations related to sensitization to pollens, the patient was advised to avoid exposure to fish food containing Mysis or Artemia species. Because aquarium fish food products with various compositions are typically manufactured in the same factory and probably run on the same production line, the risk of cross-contamination cannot be fully excluded. For this reason, the patient was advised to avoid all kinds of aquarium fish food.

Accurate identification and characterization of allergens are key elements of primary prevention. More in-depth knowledge of the role of aldolases in inducing respiratory allergy to aquarium fish food is necessary to improve diagnosis and enable effective allergen avoidance.

\section{Funding}

This study was funded by the Department of Education, Universities and Research (Project IT787-13) and the Basque Foundation for Food Quality and Safety Research (Project PA15/02) of the Government of the Basque Country.

\section{Conflicts of Interest}

The authors have no conflict of interest to declare.

\section{Previous Presentations}

The data presented in this manuscript were presented in poster format at the European Academy of Allergy and Immunology \& World Allergy Organization World Allergy \& Asthma Congress, Milan, Italy, 22-26 June 2013. The authors were awarded a prize for the best abstract presentation.

\section{References}

1. Meseguer Arce J, Villajos IMS-G, Iraola V, Carnés J, Fernández Caldas E. Occupational allergy to aquarium fish food: red midge larva, freshwater shrimp, and earthworm. A clinical and immunological study. J Investig Allergol Clin Immunol. 2013;23:462-70.

2. Cabrerizo Ballesteros $S$, de Barrio M, Baeza ML, Rubio Sotés M. Allergy to chironomid larvae (red migde larvae) in non professional handlers of fish food. J Investig Allergol Clin Immunol. 2006;16:63-8.

3. Granslo J-T, Van Do T, Aasen TB, Irgens A, Florvaag E. Occupational allergy to Artemia fish fry feed in aquaculture. Occup Med (Chic III). 2009;59:243-8.

4. Asero R, Scala E, Villalta D, Pravettoni V, Arena A, Billeri L, et al. Shrimp Allergy: Analysis of Commercially Available Extracts for In Vivo Diagnosis. J Investig Allergol Clin Immunol. 2017;27:175-82.

5. Kuehn A, Hilger C, Lehners-Weber C, Codreanu-Morel $F_{1}$ Morisset M, Metz-Favre $C$, et al. Identification of enolases and aldolases as important fish allergens in cod, salmon and tuna: component resolved diagnosis using parvalbumin and the new allergens. Clin Exp Allergy. 2013;43:811-22.

6. Gabriel MF, González-Delgado P, Postigo I, Fernández J, Soriano V, Cueva B, et al. From respiratory sensitization to food allergy: Anaphylactic reaction after ingestion of mushrooms (Agaricus bisporus) Med Mycol Case Rep. 2015;8:14-6.

7. Worm M, Jappe U, Kleine-Tebbe J, Schäfer C, Reese I, Saloga $J$, et al. Food allergies resulting from immunological crossreactivity with inhalant allergens. Allergo J Int. 2014;23:1-16.

8. Kamath SD, Rahman AM, Voskamp A, Komoda T, Rolland $J M$, O'Hehir RE, et al. Effect of heat processing on antibody reactivity to allergen variants and fragments of black tiger prawn: A comprehensive allergenomic approach. Mol Nutr Food Res. 2014;58:1144-55.

9. Taxonomy. NCBI. Available from: https://www.ncbi.nlm.nih. gov/taxonomy

Manuscript received June 29, 2017; accepted for publication September 15, 2017.

Jorge Martínez

Department of Immunology, Microbiology and Parasitology Faculty of Pharmacy and Laboratory of Parasitology and Allergy

Lascaray Research Centre University of the Basque Country Paseo de la Universidad, 7. 01006 Vitoria, Spain E-mail: jorge.martinez@ehu.es 


\section{Dysregulated Innate Lymphocytes in Patients With Primary Antibody Deficiency Treated With Intravenous Immunoglobulin}

Vigano $\mathrm{S}^{1,2}$, Trabanelli $\mathrm{S}^{2}$, Indulsi $\mathrm{F}^{1}$, Salomé $\mathrm{B}^{2}$, Harari $\mathrm{A}^{1}$, Romero $\mathrm{P}^{2}$, Helbling $\mathrm{A}^{3}$, Jandus $\mathrm{C}^{2}$, Jandus $\mathrm{P}^{4}$

${ }^{1}$ Center for Experimental Therapeutics, Department of Oncology, Faculty of Biology and Medicine, University of Lausanne, Switzerland

${ }^{2}$ Ludwig Cancer Research Center, Faculty of Biology and Medicine, University of Lausanne, Switzerland

${ }^{3}$ Department of Rheumatology, Immunology and Allergology, University Hospital/Inselspital Bern, Switzerland

${ }^{4}$ Division of Immunology and Allergology, Department of Medical Specialties, Geneva University Hospital and Medical Faculty, Switzerland

J Investig Allergol Clin Immunol 2017; Vol. 27(6): 394-396 doi: $10.18176 /$ jiaci.0200

Key words: Primary antibody deficiency. Innate lymphocytes. ILCs. NK. CD73.

Palabras clave: Deficiencia primaria de anticuerpos. Linfocitos innatos. ILCs. NK. CD73.

Primary antibody deficiencies (PADs) are the most common inherited immunodeficiencies in humans and present as a heterogeneous group of diseases [1] [Supplementary ref. 1-2]. Of these, primary hypogammaglobulinemia $(\mathrm{PH})$ is characterized by the exclusive reduction of $\mathrm{IgG}$, while $\mathrm{IgG}$ subclass deficiency (IgGSD) is characterized by a variable reduction in $\mathrm{IgG}$ subclasses. Both diseases are clinically associated with recurrent infections [Supplementary ref. 3-4]. Replacement therapy with intravenous immunoglobulin (IVIG) increases circulating IgG levels and prevents infection [2]. Recent evidence shows that IVIG administered to patients with common variable immune deficiency (CVID) also has immunomodulatory effects [3]. However, an immunologic characterization has never been performed in PH or IgGSD, and a possible immunomodulatory effect of IVIG has not been investigated.

Innate lymphoid cells (ILCs) are a family of innate immune cells belonging to the lymphoid lineage. ILCs are emerging as key effectors in a variety of physiological and pathophysiological processes [4] [Supplementary ref. 5]. Conventional natural killer (NK) cells were described as granular lymphocytes able to kill without prior sensitization, and their alteration has been described in multiple disease and treatment settings [5,6] [Supplementary ref. 6].

Treatment-naïve CVID patients presenting inflammatory conditions were recently reported to have expanded ILC frequencies [7] and reduced NK frequencies [8]. No data are available on ILC and NK cell frequencies or phenotypes in $\mathrm{PH}$ and IgGSD in patients receiving IVIG. We report the first results for longitudinally quantified and phenotypically characterized ILCs and NKs in $9 \mathrm{PH} / \mathrm{IgGSD}$ patients before treatment and over 12 months of IVIG (Supplementary Table).

Total ILCs were characterized as lineage ${ }^{-} \mathrm{CD} 16^{-} \mathrm{CD} 127^{+}$, and the ILC subsets were identified as follows: ILC1 $\left(\mathrm{CRTH} 2^{-}{ }^{-} \mathrm{Kit}^{-} \mathrm{CD}^{-} 6^{-}\right)$, ILC2 $\left(\mathrm{CRTH}^{+}{ }^{+} \mathrm{Cit}^{+-}\right)$, and ILC3 $\left(\mathrm{CRTH} 2^{-} \mathrm{cKit}^{+} \mathrm{NKp}^{+/-}{ }^{+-}\right.$(Figure, A). Total ILCs were higher in treatment-naïve patients than in healthy donors $(P \leq .05)$, with a relative decrease in the ILC3 $\mathrm{NCR}^{+}$subset $(P \leq .05$, Figure, $\mathrm{B}$ and $\mathrm{C}$ ). No differences were observed between $\mathrm{PH}$ and IgGSD patients (Figure, B-C). IVIG induced partial normalization of total ILCs and ILC3 $\mathrm{NCR}^{+}$levels, but only after several months (Figure, B and C). The expansion of ILCs in peripheral blood in treatment-naïve patients suggests a role for these cells in sustaining inflammation in PAD patients, which can be partially controlled by IVIG.

In addition to the expression of markers associated with polarization, such as CRTH2, NKP46, and cKit, we monitored CD73 as a potential contributor to immune regulation. CD73 is an ectoenzyme that is able to catalyze AMP into immunosuppressive adenosine [Supplementary ref. 7]. PH/ IgGSD patients had a decreased $\mathrm{CD} 73^{+}$ILC frequency (Supplementary Figure 1). In particular, the frequency of $\mathrm{CD}^{+}{ }^{+}$ILC1 coexpressing or not NKp46 and NKG2D was decreased even after IVIG $(P \leq .04$, Figure, D). Interestingly, deficiency in CD73 expression by B cells was previously reported in CVID patients with impaired Ig class switching [9].

We measured ILC cytokines in the serum of patients and healthy donors to investigate the functional competence of ILCs and observed a trend for increased Type1/Type 2 cytokines and IL-17 levels in patients (Supplementary Figure 2, A), which might reflect expansion of ILCs. We found a consistent trend towards a correlation between each cytokine concentration and total ILC frequency in PAD patients (Supplementary Figure 2, B).

In addition, we evaluated the frequency of total NK and NK subsets in the peripheral blood mononuclear cells of patients and healthy donors. Total NKs were defined as lineage- $\mathrm{CD} 127^{-}$ $\mathrm{CD} 16^{+/-} \mathrm{CD} 56^{+/}$. Among these, the NK subsets considered were $\mathrm{CD} 16^{+} \mathrm{CD} 56^{\mathrm{dim}}, \mathrm{CD} 16^{-} \mathrm{CD} 56^{\text {bright }}$, and immature $\mathrm{NK}$ cells $\left(\mathrm{CD} 16^{+} \mathrm{CD} 56^{-}\right.$, iNK) (Supplementary Figure, 3A), for which we also evaluated expression of NKG2D, CD73, cKit, and NKp46 (Supplementary Figure 4 and data not shown).

As previously described in CVID [8], total and $\mathrm{CD} 16^{+} \mathrm{CD} 56 \mathrm{dim} \mathrm{NK}$ frequencies were decreased in $\mathrm{PH} /$ IgGSD patients $(P \leq .05$, Supplementary Figure, $3 \mathrm{~B})$ even after IVIG therapy (Supplementary Figure 3, C). This reduction was likely due to the increased proportions of iNK $(P \leq .05$, Figure $3, \mathrm{C}$ ), a subset almost absent in healthy donors but known to be expanded in chronic viral diseases [Supplementary ref. 8]. Of note, among NK subsets, only iNK expressed detectable CD73 levels in healthy donors, although this was lost in PH/IgGDS patients despite the expansion of the iNK subset $(P \leq .05$, Supplementary Figure 4). To test NK function, we sorted NK subsets and evaluated their cytotoxicity against the K562 cell line using a chromium release assay. Consistent with previous studies, iNK and $\mathrm{CD} 16^{+} \mathrm{CD} 56^{\text {bright }}$ subsets were less cytotoxic than $\mathrm{CD} 16^{+} \mathrm{CD} 56^{\mathrm{dim}} \mathrm{NK}$ cells (Supplementary Figure 3, D). Of note, all NK subsets tested had reduced cytotoxicity in patients (Supplementary Figure 3, D). This observation, in combination 
A

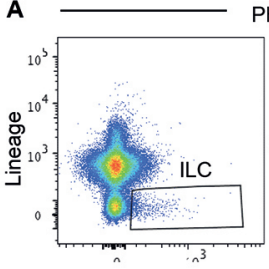

CD127

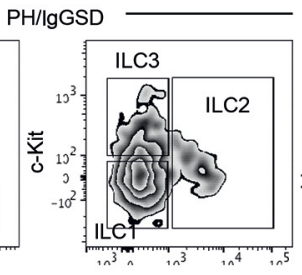

CRTH2

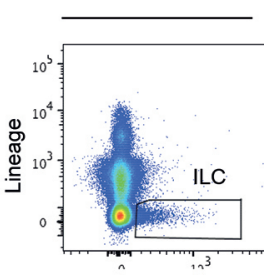

CD127

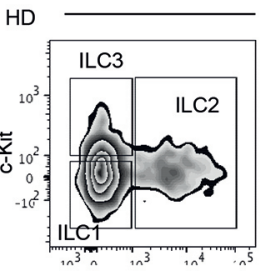

CRTH2
C ILC1

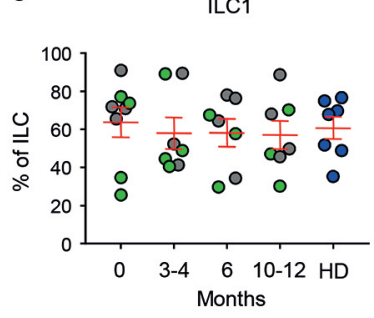

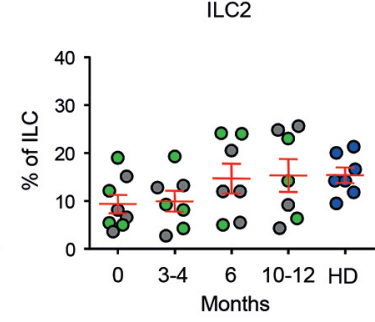

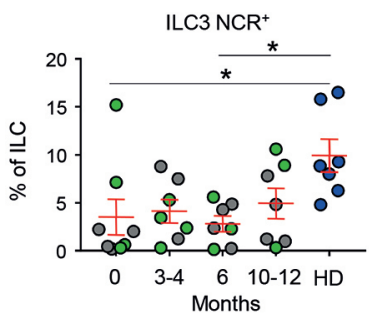

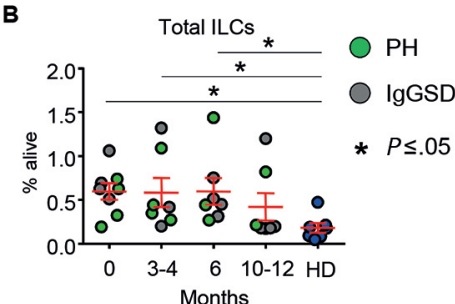

LC3 NCR-

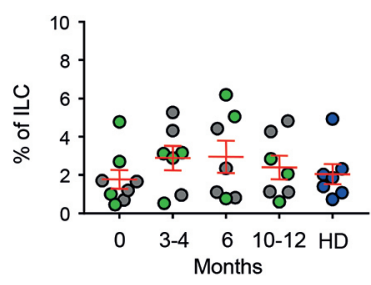

* P $\leq .05 \quad \bigcirc \mathrm{PH} \quad \bigcirc \operatorname{lgGSD}$

D
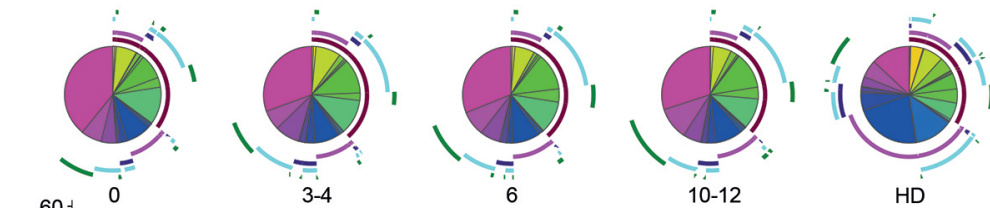

$\begin{array}{ll}6 & 10-12 \\ & \end{array}$

HD
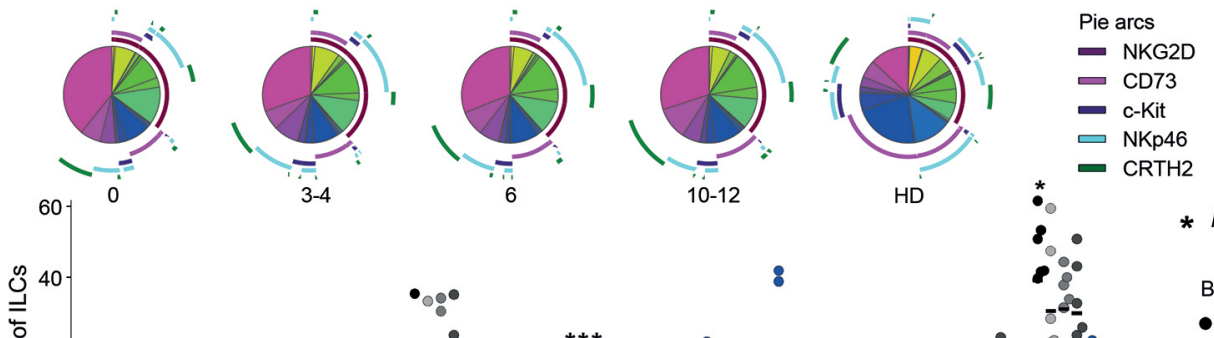

* $P \leq .04$, different from HDs

Bars (Months)

- 0

3-4

6

10-12

- HDs

Figure. Expanded ILCs in PH and IgGSD patients are partially restored upon IVIG treatment. A, Representative flow cytometry profile and gating strategy used for monitoring total ILCs and ILC subsets in PH/IgGSD patients over 12 months of IVIG treatment and in HDs. B, Proportion of total ILCs among total live lymphocytes. C, Distribution of ILC1, ILC2, and ILC3 (NCR+ or NCR ) among total ILCs in patients and in HDs. Each dot represents 1 patient or HD, and the means (SEM) are superposed. Green dots represent PH patients, gray dots represent IgGSD patients, and blue dots represent HDs. D, Expression profile of NKG2D, CD73, CKit, NKp46, and CRTH2 evaluated on total ILCs. Selection of possible combinations of the molecules depicted are shown on the $x$ axis; the percentages of the distinct cell subsets within total ILCs are shown on the $y$ axis. The pie charts summarize the data, and each slice corresponds to a certain combination of molecules. Colors in the pie charts are represented by the colored boxes at the bottom of the panel. Each dot represents 1 patient or healthy donor and means are superposed. IgGSD indicated Ig subclass deficiency; ILC, innate lymphoid cell; HD, healthy donor; IVIG, intravenous immunoglobulin.

with the increased frequency of iNK cells, suggests impaired NK differentiation and cytotoxic potential in PH/IgGSD patients. We consistently found that expression of cKit by CD16-CD56 $6^{\text {bright }} \mathrm{NK}$ was markedly reduced (Supplementary Figure 3, E); this finding was previously shown to correlate with survival, expansion, and maturation of NK cells [10]. The incapacity of IVIG to restore NK cell frequency in opposition to the normalization of ILCs may be explained by distinct developmental and homeostatic properties. NKs and some ILC1s require IL-15 for development and/or homeostasis [Supplementary ref. 9-11], whereas ILC2 and ILC3 rely on IL-7 [Supplementary ref. 9]. The requirement of IL-15 for maturation, however, can be overcome during certain infections or in some tissues by both subsets [Supplementary ref. 12-13], and even though NK progenitors express CD127 at early stages of development, CD127 is absent on mature NK cells, while it is retained on ILC1.

Patients with $\mathrm{PH} / \mathrm{IgGSD}$ are common in clinical practice and constitute a diagnostic and therapeutic challenge because of the scant information on their clinical and immunological characteristics. Ours is the first study to define quantitative and qualitative alterations in innate immunity in PH/IgGSD patients. We believe that these alterations may help to improve disease characterization. Besides a reduced Ig level, other abnormal variations in the innate immune system might contribute to morbidity. We also showed a reduction in CD73 expression in both ILCs and NK, which was previously observed in the B-cell compartment [9]. Adenosine is an immunosuppressive purine nucleoside that is generated by the catabolism of extracellular ATP via CD39/CD73 
ectoenzymes. In contrast with the action of CD39, the activity of CD73 is virtually irreversible, thus making it a crucial checkpoint in this axis. The decrease in CD73 levels may contribute to the pathogenesis of PAD by reducing circulating immunosuppressive adenosine [Supplementary ref. 7]. Our data point to an immunomodulatory effect of IVIG on the innate immune system in $\mathrm{PH} / \mathrm{IgGSD}$ patients. However, further controlled studies in larger cohorts are needed to confirm our observations and to define their correlation with clinical outcomes.

The study was performed according to local legislation, ethical guidelines and usual clinical practice. The patients gave their informed consent for anonymized data to be included in a scientific publication.

\section{Acknowledgments}

We kindly acknowledge the participation of the patients and healthy donors.

\section{Funding}

Peter Jandus was supported by a grant from CSL Behring.

\section{Conflicts of Interest}

The authors do not have any conflict of interest.

\section{Previous Presentations}

These data were presented in part at SSAI 2016, Montreux, Switzerland.

\section{References}

1. Fazlollahi MR, Pourpak $Z$, Hamidieh AA, Movahedi $M$, Houshmand M, Badalzadeh M, et al. Clinical, Laboratory and Molecular Findings of 63 Patients with Severe Combined Immunodeficiency. A Decade s Experience. J Investig Allergol Clin Immunol. 2017;27:299-304.

2. Bienvenu B, Cozon G, Hoarau C, Pasquet M, Cherin P, Clerson $P$, et al. Does the route of immunoglobin replacement therapy impact quality of life and satisfaction in patients with primary immunodeficiency? Insights from the French cohort "Visages". Orphanet J Rare Dis. 2016;11:83.

3. Matucci A, Maggi E, Vultaggio A. Mechanisms of action of Ig preparations: immunomodulatory and anti-inflammatory effects. Front Immunol. 2015;5:690.

4. Klose CS, Artis D. Innate lymphoid cells as regulators of immunity, inflammation and tissue homeostasis. Nat Immunol. 2016;17:765-74.

5. Zhang C, Tian Z. NK cell subsets in autoimmune diseases. J Autoimmun. 2017;83:22-30.

6. Tosello-Trampont A, Surette FA, Ewald SE, Hahn YS. Immunoregulatory Role of NK Cells in Tissue Inflammation and Regeneration. Front Immunol. 2017;8:301.

7. Cols M, Rahman A, Maglione PJ, Garcia-Carmona Y, Simchoni $\mathrm{N}$, Ko HB, et al. Expansion of inflammatory innate lymphoid cells in patients with common variable immune deficiency. J Allergy Clin Immunol. 2016;137:1206-15.
8. Ebbo M, Gerard L, Carpentier S, Vely F, Cypowyj S, Farnarier C, et al. Low Circulating Natural Killer Cell Counts are Associated With Severe Disease in Patients With Common Variable Immunodeficiency. EbioMedicine. 2016;6:222-30.

9. Schena F, Volpi S, Faliti CE, Penco F, Santi S, Proietti M, et al. Dependence of immunoglobulin class switch recombination in $B$ cells on vesicular release of ATP and CD73 ectonucleotidase activity. Cell Rep. 2013;3:1824-31.

10. Colucci F, Di Santo JP. The receptor tyrosine kinase c-kit provides a critical signal for survival, expansion, and maturation of mouse natural killer cells. Blood. 2000;95:98491.

Manuscript received July 11, 2017; accepted for publication September 20, 2017.

Peter Jandus

Division of Immunology and Allergology Department of Medical Specialties University Hospital and Medical Faculty Rue Gabrielle Perret-Gentil 4

1211 Geneva 14 Switzerland E-mail: peter.jandus@hcuge.ch 